\title{
Seasonal Predictability of Daily Rainfall Characteristics in Central Northern Chile for Dry-Land Management
}

\author{
KOEN VERBIST \\ International Centre for Eremology, Department of Soil Management, Ghent University, Ghent, Belgium, and Water Centre \\ for Arid Zones in Latin America and the Caribbean (CAZALAC), La Serena, Chile \\ ANDREW W. ROBERTSON \\ International Research Institute for Climate and Society, Columbia University, Palisades, New York \\ WiM M. CORNELIS AND DONALD GABRIELS \\ International Centre for Eremology, Department of Soil Management, Ghent University, Ghent, Belgium
}

(Manuscript received 18 August 2009, in final form 23 April 2010)

\begin{abstract}
The seasonal predictability of daily winter rainfall characteristics relevant to dry-land management was investigated in the Coquimbo region of central northern Chile, with focus on the seasonal rainfall total, daily rainfall frequency, and mean daily rainfall intensity on wet days at the station scale. Three approaches of increasing complexity were tested. First, an index of the simultaneous El Niño-Southern Oscillation (ENSO) was regressed onto May-August (MJJA) observed precipitation; this explained $32 \%$ of station-averaged rainfall-amount variability, but performed poorly in a forecasting setting. The second approach used retrospective seasonal forecasts made with three general circulation models (GCMs) to produce downscaled seasonal rainfall statistics by means of canonical correlation analysis (CCA). In the third approach, a nonhomogeneous hidden Markov model (nHMM) driven by the GCM's seasonal forecasts was used to model stochastic daily rainfall sequences. While the CCA is used as a downscaling method for the seasonal rainfall characteristics themselves, the nHMM has the ability to simulate a large ensemble of daily rainfall sequences at each station from which the rainfall statistics were calculated. Similar cross-validated skill estimates were obtained using both the CCA and nHMM, with the highest correlations with observations found for seasonal rainfall amount and rainfall frequency (up to 0.9 at individual stations). These findings were interpreted using analyses of observed rainfall spatial coherence, and by means of synoptic rainfall states derived from the HMM. The downscaled hindcasts were then tailored to meteorological drought prediction, using the standardized precipitation index (SPI) based on seasonal values, the frequency of substantial rainfall days $(>15 \mathrm{~mm}$; FREQ15) and the daily accumulated precipitation deficit. Deterministic hindcasts of SPI showed high hit rates, with high ranked probability skill score for probabilistic hindcasts of FREQ15 obtained via the nHMM.
\end{abstract}

\section{Introduction}

Climate variability can have serious social impacts in semiarid regions, especially for farmers who depend on rain-fed agriculture and on livestock production based on natural vegetation. In the Coquimbo region in central northern Chile, where rainfall amounts often drop under the limit for crop growth, a lack of rainfall results in

Corresponding author address: Koen Verbist, Dept. of Soil Management, Coupure Links 653, 9000 Ghent, Belgium.

E-mail: Koen.Verbist@UGent.be a crisis situation for society. Over US $\$ 2.6$ million were spent during the severe drought of 2007 to support affected families and farmers in the Coquimbo region, repair damage, recover degraded soils, and increase irrigation programs (MINAGRI 2008). Although these measures reduced the negative effects of the 2007 drought, they did not address all affected families because of budget limitations, nor did they increase preparedness and resilience to future droughts. Of the 16307 rural families in Chile seeking monetary aid to overcome the negative aspects of the 2007 drought, more than $75 \%$ indicated suffering a lack of sufficient water for irrigation 
and domestic use, and they observed harvest losses for the crops grown for their own consumption [J. Castillo, Fondo de Solidaridad e Inversión Social (FOSIS), 2008, personal communication]. A typical problem here is the lack of preparedness prior to these natural events, making any governmental action afterward less cost effective. Despite the need, the current Drought Alleviation Plan formulated by the Chilean government for the region (FOSIS 2008) does not include strategies for drought early warning, and the feasibility of such a system has yet to be demonstrated.

The El Niño-Southern Oscillation (ENSO) is known to have a strong impact on winter rainfall over central northern Chile, with positive rainfall anomalies during El Niño events, and below-normal rainfall mostly associated with La Niña conditions (Aceituno 1988; Aceituno et al. 2009; Falvey and Garreaud 2007; Montecinos and Aceituno 2003; Pittock 1980; Quinn and Neal 1983; Rubin 1955; Rutllant and Fuenzalida 1991; Garreaud et al. 2009). However, the associated seasonal predictability and forecast skill levels from current dynamical seasonal prediction models (e.g., Goddard et al. 2003) have not yet been assessed in detail for the statistics of local daily weather that are likely to be most pertinent to meteorological drought.

In this paper we document the characteristics of daily winter rainfall from station observations over the Coquimbo region, and assess their seasonal predictability from three current seasonal prediction general circulation models (GCMs), together with statistical techniques to "downscale" and tailor the output from these relatively course resolution models to the station scale. While GCMs typically misrepresent the characteristics of local daily rainfall, statistical downscaling can often correct such biases and provide probabilistic rainfall simulations that are well calibrated against local station data (Hughes and Guttorp 1994; Robertson et al. 2009). Our analysis of the station rainfall data begins with a decomposition of seasonal rainfall amounts into rainfall frequency and the mean rainfall amount falling on wet days; that is, the rainfall intensity. The correlation between rainfall data from stations separated by increasing distances; that is, the spatial "coherence," for each of the seasonal anomaly types (rainfall amount, intensity, and frequency) across the region is then investigated. Spatial coherence provides a measure of the potential seasonal predictability, because there is no a priori reason for the seasonal anomalies to differ between locations, except due to local-scale processes; Moron et al. (2007) argued that these are dominated by unpredictable noise over homogeneous regions. From such analyses of seasonal anomalies, rainfall frequency at local scale has been shown to be generally more spatially coherent in the tropics, and thus potentially more predictable on seasonal time scales (Moron et al. 2007), but it has not heretofore been investigated for the midlatitudes such as is done in this study. For a climatically homogeneous region, even in regions of complex terrain like Coquimbo, high spatial coherence would be an indicator of potential predictability, although the reverse is not necessarily the case.

To gain insight into the nature of the daily rainfall variability and its year-to-year modulations in more detail, we model the sequences of station rainfall in terms of different daily rainfall patterns, or rainfall states, as determined by a hidden Markov model (HMM). The HMM can simulate stochastic daily sequences of rainfall occurrence with a specific rainfall intensity, by estimating the transition probabilities between daily weather patterns or states. The Markov property requires that the probability of occurrence of a particular state on a given day only depends on the previous day's state. The set of states needed to describe the local daily rainfall characteristics are determined from observed rainfall records; the states are not directly observed and are as such hidden. In the homogeneous HMM, the transition probabilities from one state to the other are not allowed to vary in time. In its nonhomogeneous form (nHMM), the transition probability between states can vary in time, allowing external inputs to influence the rainfall characteristics between one year and another. Seasonal GCM predictions can be used to determine these inputs, creating an effective method to downscale them to most probable daily rainfall sequences at the station scale, training the nHMM on each year for which GCM seasonal hindcasts are available (Charles et al. 1999; Robertson et al. 2004, 2006, 2009). Encouraging results were reported by Bellone et al. (2000), who used a combined climate index, including wind, temperature and relative humidity fields, together with an nHMM to construct a model for daily rainfall amounts. In addition to probabilistic downscaling using the nHMM, we apply a simpler method based on canonical correlation analysis (CCA) to the seasonally averaged statistics themselves (seasonal amount, daily rainfall frequency, and mean daily intensity), in order to obtain downscaled estimates of their seasonal predictability.

The work in this paper aims to lay the foundations for constructing (meteorological) drought early warning systems, through analyses of daily rainfall and by estimating seasonal predictability. The rainfall data and GCMs are described in section 2, with the statistical methods outlined in section 3. The results of the station rainfall analyses and retrospective forecasts of drought indices are presented in section 4 , with the concluding remarks in section 5 . 


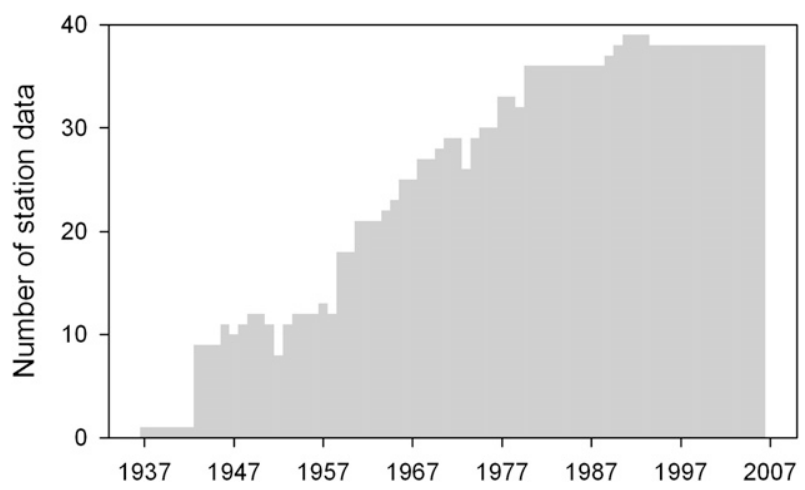

FIG. 1. Number of stations with May-Aug station rainfall data used in the analysis.

\section{Data}

\section{a. Observed rainfall data}

The analysis of daily rainfall was based on data from 42 stations in the Coquimbo region, obtained from the Chilean Water Authority (DGA) covering the period 1937-2006. However, it should be noted that data series were only available for a limited number of stations $(<13)$ during the first part $(1937-58)$ of this period, reaching 38 stations from 1990 onward (Fig. 1).

Figures 2 and 3 show the seasonality and spatial distribution of rainfall, together with a decomposition of seasonal rainfall amount into the frequency of occurrence of daily rainfall, and the mean daily intensity of rainfall on wet days $(>1 \mathrm{~mm})$. A distinct wet season covering the period May-August (MJJA) accounting for $85 \%$ of the annual rainfall amount was identified in the dataset (Fig. 2) and was used for further analysis. Rainfall intensities were on average higher during the wet season, with maximum daily rainfall amounts observed between 100 and $207 \mathrm{~mm}$ in $22 \%$ of the years. In terms of the seasonality within the MJJA season, average rainfall intensities show little within-season systematic modulation, while rainfall frequency shows a clear seasonal modulation with a peak in July.

Spatial rainfall characteristics in the Coquimbo region for this period are given in Fig. 3, indicating clear geographical modulation of rainfall. Seasonal rainfall amounts range between $43 \mathrm{~mm}$ in the north and $270 \mathrm{~mm}$ in the pre-Andean cordillera, respectively (at $840 \mathrm{~m}$ above sea level), tending to increase eastward toward the Andes, because orographic effects, and from north to south, because of an increased influence of the midlatitude storm track. Rainfall frequency is very low, ranging from 4 to 13 wet days per season on average, and is more geographically modulated than mean rainfall intensity (range of 10-24 mm day ${ }^{-1}$ ). The larger spatial variation of rainfall frequency compared to mean intensity is
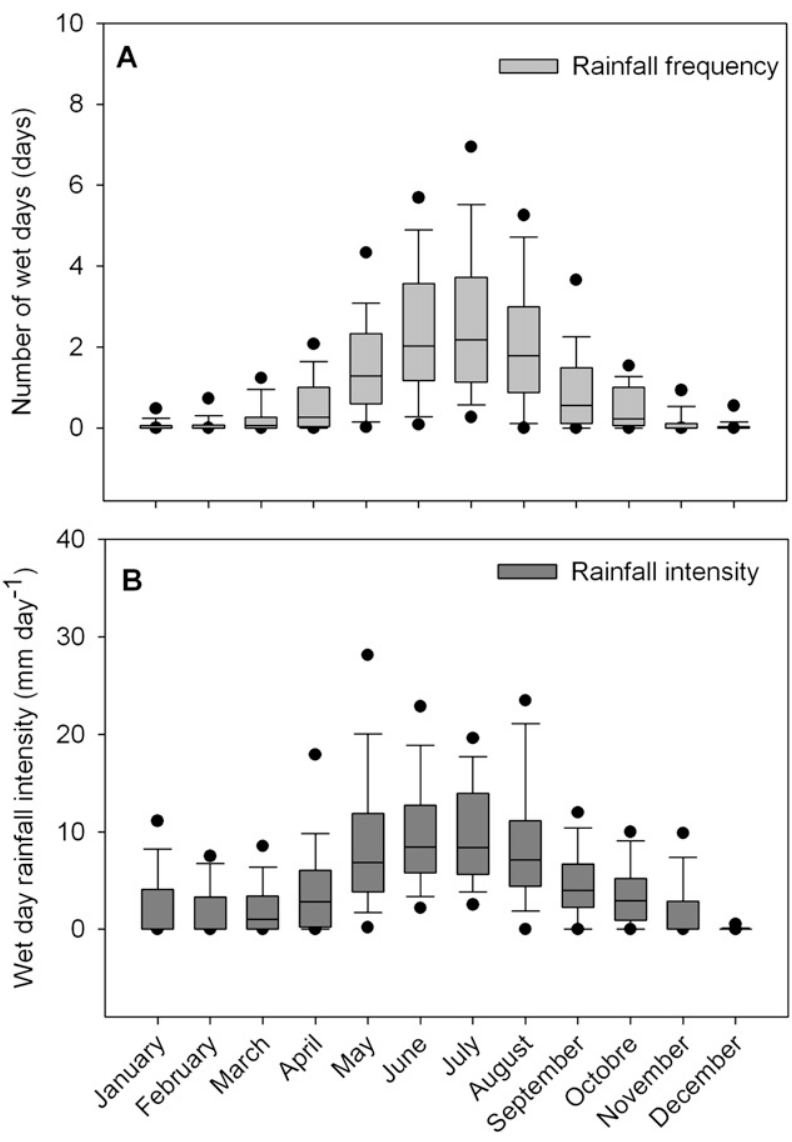

FIG. 2. Box plots of rainfall seasonality in the Coquimbo region; (a) number of wet days $(>1 \mathrm{~mm})$ and (b) rainfall intensity $\left(\mathrm{mm} \mathrm{day}^{-1}\right)$ on wet days. The whiskers indicate the 10 th and 90 th percentiles, and the dots the 5 th and 95 th percentiles.

consistent with the smaller within-season monthly modulation of the latter in Fig. 2, and with the frontal nature of winter rainfall over the region (Aceituno 1988).

\section{b. Seasonal forecast models}

Retrospective seasonal MJJA precipitation forecasts initialized on 1 April were obtained from three GCMs: the European Centre Hamburg Model (ECHAM4.5; Roeckner et al. 1996), the National Centers for Environmental Prediction (NCEP) Climate Forecast System (CFS; Saha et al. 2006), and the Community Climate Model (CCM 3.6; Hurrell et al. 1998). The ECHAM and CCM are atmospheric GCMs that are both driven with the same constructed-analog (CA) predictions of global sea surface temperature (SST) in a two-tiered approach (Li and Goddard 2005). The two-tier approach has been used as the basis of the International Research Institute (IRI) operational seasonal forecast system since 1997 (Barnston et al. 2010), while studies indicate comparable predictive performance of one- and two-tier approaches (Kumar et al. 2008). We thus refer to them in the following 

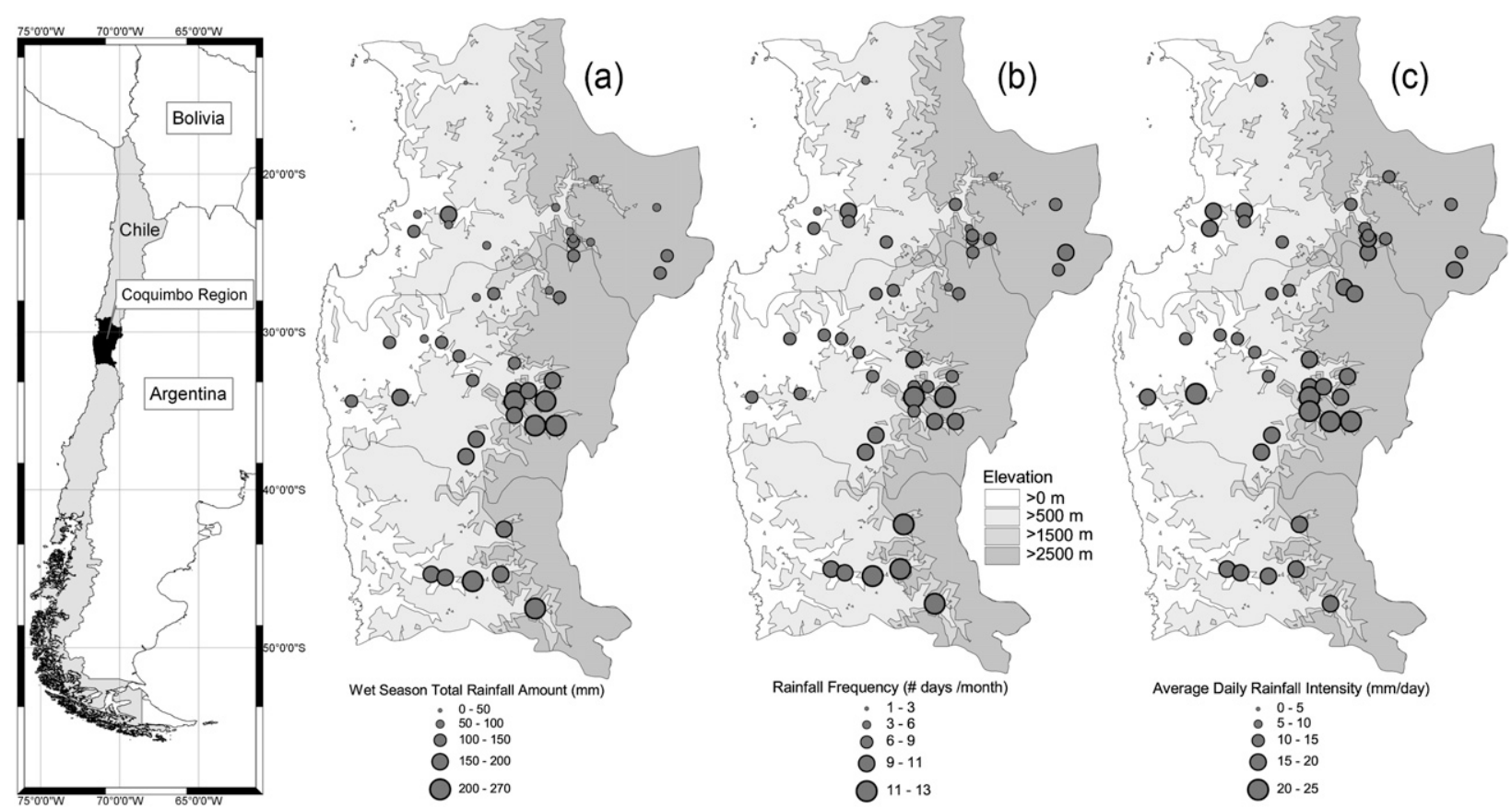

FIG. 3. Average rainfall characteristics during the wet season (May-Aug): (a) seasonal rainfall amount; (b) rainfall frequency; (c) mean daily rainfall intensity for the period 1937-2006. A locator map indicates the position of the Coquimbo region within Chile and South America.

as ECHAM-CA and CCM-CA, respectively. The CFS is a coupled ocean-atmosphere GCM with initialization of the atmosphere, ocean, and land surface conditions through data assimilation. For all models, the ensemble mean (over 24 members for ECHAM and CCM and 15 members for CFS) gridded precipitation was used at a resolution of $\mathrm{T} 62\left(\sim 1.9^{\circ}\right)$ for $\mathrm{CFS}$ and $\mathrm{T} 42\left(\sim 2.8^{\circ}\right)$ for ECHAM-CA and CCM-CA, over the domain $20^{\circ}-40^{\circ} \mathrm{S}$ and $65^{\circ}-85^{\circ} \mathrm{W}$. Seasonal MJJA precipitation hindcasts were available for the 1981-2002 period for CCM-CA and ECHAM-CA, and for the 1981-2005 period in the case of CFS.

\section{Statistical methods}

\section{a. Spatial coherence analysis}

Estimates of spatial coherence of interannual rainfall station anomalies are used as indicators of potential seasonal predictability following Moron et al. (2007). The number of spatial degrees of freedom (DOF) gives an empirical estimate of the spatial coherence in terms of empirical orthogonal functions (EOFs), with higher values denoting lower spatial coherence:

$$
\mathrm{DOF}=M^{2} / \sum_{j=1}^{M} e_{j}^{2},
$$

where $e_{j}$ are the eigenvalues of the correlation matrix formed from the station seasonal-mean time series and $M$ is the number of stations.

A second measure of the spatial coherence of interannual anomalies is given by the interannual variance of the standardized precipitation anomaly index, $\operatorname{var}(\mathrm{SAI})$, which is constructed from the station average of the standardized rainfall anomalies (Katz and Glantz 1986):

$$
\operatorname{var}\left(\mathrm{SAI}_{i}\right)=\operatorname{var}\left[\frac{1}{M} \sum_{j=1}^{M} \frac{\left(x_{i j}-\bar{x}_{j}\right)}{\sigma_{j}}\right],
$$

where $\bar{x}_{j}$ is the long-term time mean over $i=1, \ldots, N$ years and $\sigma_{j}$ is the interannual standard deviation for station $j$. The $\operatorname{var}(\mathrm{SAI})$ is a maximum when all stations are perfectly correlated, $\operatorname{var}(\mathrm{SAI})=1$, and a minimum when the stations are uncorrelated, resulting in a $\operatorname{var}(\mathrm{SAI})=1 / M$.

\section{b. Hidden Markov model}

A state-based Markovian model was used to model daily rainfall sequences at the 42 stations, in order to gain insight into the daily rainfall process, and as a means to downscale daily rainfall sequences (downscaling in space and time). We use the approach developed by Hughes and Guttorp (1994) for rainfall occurrence, 
while additionally modeling rainfall amounts. The hidden Markov model used here is described fully in Robertson et al. $(2004,2006)$. In brief, the time sequence of daily rainfall measurements on the network of stations is assumed to be generated by first-order Markov chain of a few discrete hidden (i.e., unobserved) rainfall states. For each state, the daily rainfall amount at each station is modeled by a zero-amount delta function for dry days and an exponential for days with nonzero rainfall. To apply the HMM to downscaling, rainfall state transition probabilities were allowed to vary with time, resulting in the nonhomogeneous HMM (nHMM). In this study, transition probabilities between states are modeled as functions of predictor variables, in our case GCM predictions of MJJA seasonal-averaged precipitation over the region $\left(5^{\circ}-40^{\circ} \mathrm{S}, 100^{\circ}-50^{\circ} \mathrm{W}\right)$. For data compression, a conventional principal components (PC) analysis was first applied to the gridded seasonal-averaged GCM (CFS) precipitation fields, with each gridded precipitation value standardized by its interannual standard deviation at that gridpoint, selecting here the leading PC as the input variable to the nHMM. The leading PC represented $36 \%$ of the model variance and showed a correlation coefficient of 0.72 with the observed average rainfall in the region (period 1980-2005). The nHMM was trained under leave-three-years-out cross-validation, using the CFS 15-member ensemble mean. To make downscaled simulations, we used each CFS ensemble member in turn, and generated 10 stochastic realizations for each one, yielding an ensemble prediction of 150 daily rainfall sequences for each MJJA season, providing a probabilistic forecast (Robertson et al. 2009).

The seasonal statistics of interest (seasonal amount, daily rainfall frequency, and mean daily intensity on wet days) were then computed from these simulated rainfall sequences and compared to their observed counterparts at each station.

\section{c. Downscaling of seasonal forecasts using canonical correlation analysis}

In addition to the nHMM, downscaling was also carried out by applying canonical correlation analysis (CCA) directly to the seasonal rainfall statistics of interest. The CCA regularizes the high-dimensional regression problem between a spatial field of predictors and predictands by reducing the spatial dimensionality via principal component analysis and thus minimizes problems of overfitting and multicolinearity (Tippett et al. 2003). Cross validation was used to determine the truncation points of the PC and CCA time series, via the Climate Predictability Tool (CPT) software toolbox (more information available online at http://iri.columbia.edu/outreach/software/). As predictor datasets the retrospective seasonal MJJA
TABLE 1. DOF and var(SAI)] for seasonal rainfall amount (RAm), rainfall intensity (RI), and rainfall frequency $(\mathrm{RF})$ for each province and altitude class in the Coquimbo region.

\begin{tabular}{|c|c|c|c|c|c|c|c|}
\hline & \multirow[b]{2}{*}{$N^{*}$} & \multicolumn{3}{|c|}{ DOF } & \multicolumn{3}{|c|}{$\operatorname{Var}(\mathrm{SAI})$} \\
\hline & & RAm & RI & $\mathrm{RF}$ & RAm & RI & $\mathrm{RF}$ \\
\hline \multicolumn{8}{|l|}{ Province } \\
\hline Elqui & 12 & 9.14 & 17.26 & 11.85 & 0.30 & 0.20 & 0.26 \\
\hline Limari & 24 & 4.07 & 7.13 & 5.10 & 0.44 & 0.31 & 0.40 \\
\hline Choapa & 8 & 5.14 & 7.17 & 6.18 & 0.41 & 0.34 & 0.37 \\
\hline \multicolumn{8}{|l|}{ Altitude class } \\
\hline $0-500 \mathrm{~m}$ & 13 & 5.05 & 8.91 & 6.33 & 0.40 & 0.28 & 0.36 \\
\hline $500-1500 \mathrm{~m}$ & 25 & 5.10 & 7.86 & 6.38 & 0.40 & 0.31 & 0.35 \\
\hline$>1500 \mathrm{~m}$ & 6 & 13.57 & 21.01 & 15.09 & 0.23 & $0.16^{+}$ & 0.21 \\
\hline
\end{tabular}

* Number of stations used.

${ }^{+}$Minimum var(SAI) value (mean correlation equals zero).

precipitation forecasts by the three GCMs discussed in section $2 \mathrm{~b}$ were used in conjunction with the MJJA seasonal rainfall at the 42 stations of the Coquimbo region. The three CCA models were trained and tested over the 1981-2000 period, with a cross-correlation window of five years (i.e., leaving out two years on either side of the verification value). As employed here, the CCA provides a deterministic mean forecast value, in contrast to the nHMM probabilistic ensemble.

\section{Results}

\section{a. Spatial coherence of rainfall anomalies}

As a first step toward assessing the seasonal predictability of rainfall at local scale, we begin with an analysis of spatial coherence for each of the three rainfall characteristics: seasonal amount, rainfall frequency, and mean daily intensity. Based on Fig. 3, spatial coherence estimates were made separately for the three provinces (from north to south: Elqui, Limari, and Choapa) and for three altitude classes (from west to east: 0-500 m, 500-1500 m and $>1500 \mathrm{~m}$; Fig. 3). Table 1 shows both the degrees of freedom and the variance of the standardized anomaly index for these sub datasets. The highest DOF and lowest var(SAI) was observed for the Elqui province in the north, indicating lowest spatial coherence of seasonal anomalies, consistent with its more arid nature and more sporadic rainfall. A similar tendency was found when looking at altitude influences, with lowest spatial coherence at highest altitudes $(>1500 \mathrm{~m})$, caused by orographic influences on rainfall variability.

The dependence of spatial coherence characteristics was analyzed as a function of time scale using station autocorrelation. Figure 4 shows the averaged Pearson correlation between each station pair plotted against distance, for rainfall amount, intensity, and frequency 


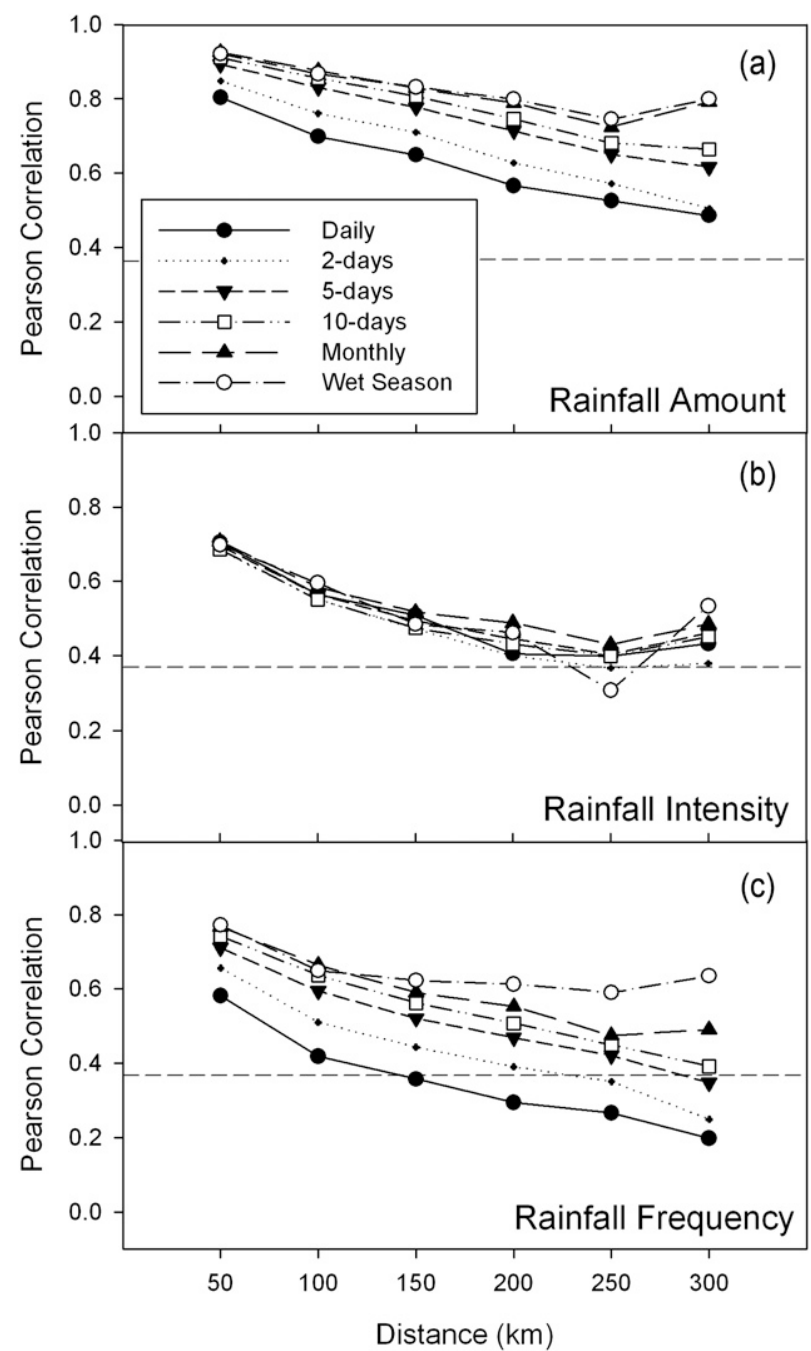

FIG. 4. Spatial correlation function of (a) daily rainfall amount, (b) rainfall intensity, and (c) rainfall frequency for the daily, 2-day, 5-day, 10-day, 30-day, and seasonal-averaging periods. The 1/e decorrelation value is shown as a dashed line.

averaged over several different time windows from daily to seasonal. Taking a value of $1 / e(0.37)$ as the decorrelation distance (Dai et al. 1997; Moron et al. 2007; New et al. 2000; Ricciardulli and Sardeshmukh 2002; Smith et al. 2005), anomalies of rainfall amount were found to be significantly correlated at all temporal scales for all stations in the region. A similar observation can be made for rainfall intensity. Rainfall frequency is uncorrelated beyond $150 \mathrm{~km}$ for the daily and twice-daily time scales, but becomes more highly correlated on longer time scales. This increase in spatial correlation on longer time scales is also found for rainfall amount, but not for intensity. Similar findings were reported by Moron et al. (2007) for tropical rainfall, where it was argued that this increase toward the seasonal scale indicates a common regional seasonal climate forcing on these two rainfall characteristics. Thus, while the occurrence and amount of rainfall at individual stations contain a random element on any particular day, this locally random element becomes averaged out in time because 1) the atmospheric synoptic storms that impact the region are large scale and tend to persist over several days (Figs. 6 and 7) impacting most stations, and 2) the large-scale impact of ENSO is at the seasonal scale (section 4c). The spatial autocorrelation function is near-linear and time integration makes the stations more coherent, indicating that the seasonal function is a superposition of daily and seasonal effects, and also that the daily rainfall shows an organized, regional pattern repeated across the season.

In contrast to rainfall occurrences and amounts, rainfall intensity does not exhibit any increase in coherence when integrated over time and appears just as coherent at the daily scale. A distance of $200 \mathrm{~km}$ could be identified as the decorrelation distance for rainfall intensities between two stations in the region. This is much larger than that found by Moron et al. (2007) in the tropics, but is consistent with the advective character of rainfall in the Coquimbo region, associated with extratropical cyclones with large spatial scales (Montecinos and Aceituno 2003). The examination of spatial coherence statistics in this subsection indicates that seasonal rainfall amounts and frequencies are likely to be more predictable than mean daily rainfall intensities. However, the differences in spatial coherence between these three seasonal quantities are somewhat less than that found by Moron et al. (2007) in tropical regions.

\section{b. Daily rainfall states}

Given the high spatial coherence of rainfall in the region, we next look in more detail at the evolution of daily rainfall by identifying a small set of typical daily rainfall states (or patterns) and the transitions between them from day to day, using a hidden Markov model. To identify an appropriate number of rainfall states, the log-likelihood of HMMs was computed under cross validation with up to 10 states, resulting in an increase in log-likelihood for a small number of states, leveling off at higher numbers. This is typical because the rainfall process in nature is more complex than the simple HMM, so that models with more parameters fit the observed rainfall data better, even under cross validation. For diagnostic purposes, however, we seek a model with a small number of states for interpretability, and a model based on four rainfall states was thus chosen as a compromise. Using the maximum likelihood approach, the HMM parameters were estimated from the entire dataset of 7872 days, measured at the 42 rainfall stations, applying 


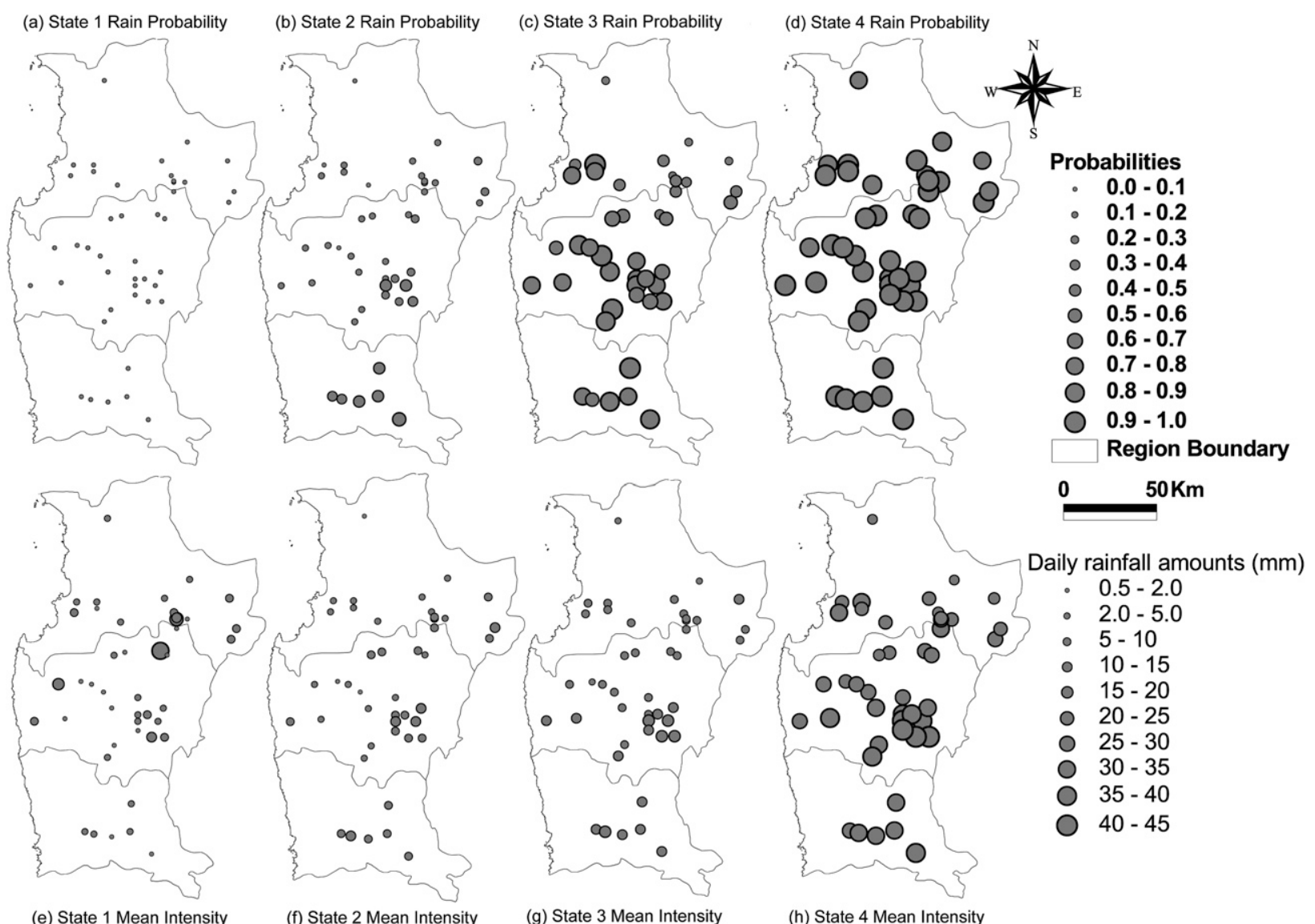

(e) State 1 Mean Intensity

(f) State 2 Mean Intensity

(g) State 3 Mean Intensity

(h) State 4 Mean Intensity

FIG. 5. Four-state HMM rainfall parameters. (a)-(d) Probabilities of rainfall occurrence and (e)-(h) mean rainfall intensities (i.e., wet-day amounts).

the iterative expectation-maximization (EM) algorithm (Dempster et al. 1977; Ghahramani 2001). The algorithm was initialized 10 times from random seeds, selecting the run with the highest log-likelihood.

The four rainfall states thus obtained are shown in Fig. 5 in terms of their rainfall characteristics, showing the probability of rainfall occurrence at each station (Figs. 5a-d), and the average rainfall intensity on wet days (Figs. $5 \mathrm{e}-\mathrm{h}$ ). States were ordered from overall driest to wettest. This ordering shows a dry state 1 with rainfall probabilities near zero at all stations and three states with increasing probabilities for rainfall and generally larger rainfall amounts on wet days. The spatial pattern of state 2 resembles that of the mean characteristics seen in Fig. 3, with more-frequent rainfall in the south and at higher altitudes. State 3 represents the rainfall events where rainfall is probable at most locations excluding the most northern ones, while rainfall intensities remain relatively small. State 4 can be interpreted as the very wet state, with high rainfall probabilities over the whole region and large rainfall intensities.
When looking at the matrix of day-to-day transition probabilities between the four states (Table 2), it can quickly be seen that state 1 is the most persistent state, but it is also the state to which the wetter states 2 and 3 are most likely to evolve. State 4 , the very wet state, has an almost equal probability for each of the states to follow it, indicating that states 2 and 3 tend to be intermediate in the transitions from a wet period to a dry period.

A visual interpretation of the temporal evolution is given in Fig. 6, showing the most probable daily sequence of the four states that occurred over the 70-winter record (1937-2006) of daily rainfall, obtained using the dynamical programming Viterbi algorithm (Forney 1978). Once the parameters of the HMM have been estimated from the rainfall data, the Viterbi algorithm uses the HMM state parameters in conjunction with the rainfall data to assign each day of the historical record to a particular state. This resulted on average in 105 days per season of state $1(85.4 \%)$, 10 days of state $2(7.7 \%)$, and 5 days of state $3(4.2 \%)$. 
TABLE 2. Transition matrix for the 4-state HMM. "From" states occupy the rows; "to" states occupy the columns. Thus, the probability of a transition from state 2 to state 1 is 0.56 .

\begin{tabular}{ccccc}
\hline \hline & \multicolumn{4}{c}{ To state } \\
\cline { 2 - 5 } From state & 1 & 2 & 3 & 4 \\
\hline 1 & 0.92 & 0.05 & 0.02 & 0.01 \\
2 & 0.56 & 0.22 & 0.12 & 0.09 \\
3 & 0.47 & 0.25 & 0.19 & 0.09 \\
4 & 0.23 & 0.28 & 0.22 & 0.27 \\
\hline
\end{tabular}

The very wet state 4 occurred on only 3 days $(2.7 \%)$ on average during each MJJA season of the 70-year period, but on average $56 \%$ of total seasonal rainfall was observed on these very wet days. The horizontal traces in Fig. 6 illustrate graphically the high intermittency of rainfall over the region, with individual rainfall events often lasting several days and being made up of days from several of the wetter states. On average, no obvious seasonality is apparent across the season.

Figure 7 shows composite sea level pressure (SLP) fields from the NCEP-National Center for Atmospheric Research (NCAR) reanalysis data (Kalnay et al. 1996), obtained by averaging over the days falling into each state and plotting them as an anomaly from the longterm MJJA average. The state SLP anomaly patterns demonstrate the well-known relationship between rainfall in central Chile and synoptic-wave disturbances (Falvey and Garreaud 2007). The wet states $2-4$ are associated with a similar wave pattern with an anomalous trough over the Chilean coast extending east of the Andes, but with increasing trough intensity as a function of rainfall, while the dry state 1 (note finer contour interval in Fig. 7a) has the opposite footprint of anomalous anticyclonic conditions over central Chile. The tendency seen in the state sequence for multiday persistent rainfall events made up of several states (Fig. 6) shows that this anomalous low pressure pattern, once established, often remains approximately stationary while growing and decaying in situ; the partitioning of the associated rainfall events into states 2-4 demonstrates the strong dependence of rainfall probability and intensity on the amplitude of this synoptic weather pattern.

\section{c. ENSO influence on seasonal rainfall characteristics}

The interannual variability over the Coquimbo region can be interpreted in terms of the HMM's state sequence, with more instances of the wetter states during wet winters. Before proceeding with that analysis, we first summarize the well-known ENSO influence on the seasonal statistics of rainfall (MJJA amount, rainfall frequency, and mean daily intensity) averaged over all 42 stations. The relationship between seasonal rainfall amounts and ENSO is plotted in Fig. 8 in terms of the Niño-3.4 index. All but one (the year 1984) of the very wet winters $(>100 \mathrm{~mm}$ above average rainfall) have been associated with the warm ENSO phase, with all of these ENSO events in their developing phase over the MJJA season. The cold ENSO phase has almost always been associated with below-normal rainfall, although several years have less than normal rainfall without strong La Niña characteristics. The Pearson correlation between Niño-3.4 and MJJA rainfall amount for the entire period $1937-2006$ is 0.57 , which is statistically

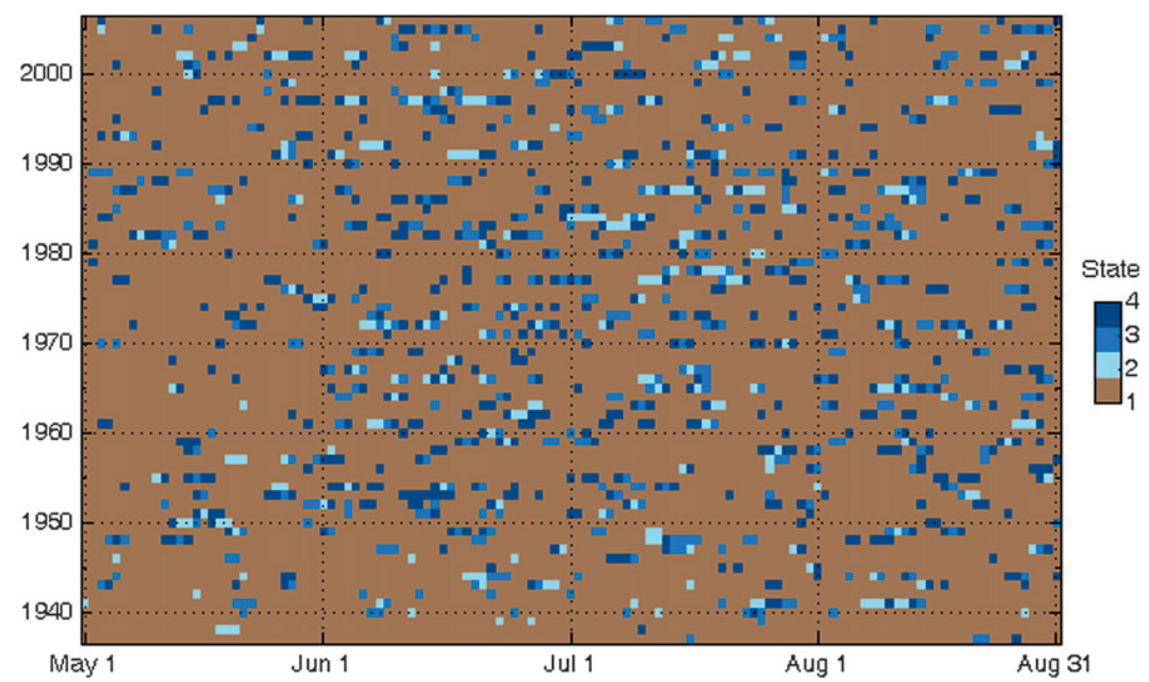

FIG. 6. The most probable HMM state sequence obtained using the Viterbi algorithm. Rainfall states are indicated from driest (state 1) to wettest (state 4) on the color bar. 
a) State 1 SLP anomaly

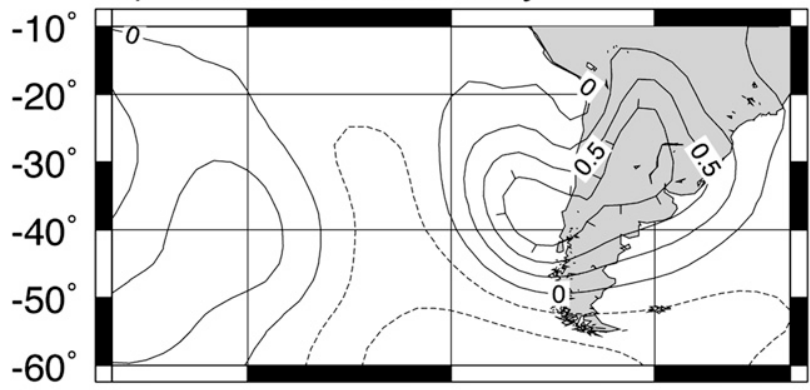

c) State 3 SLP anomaly

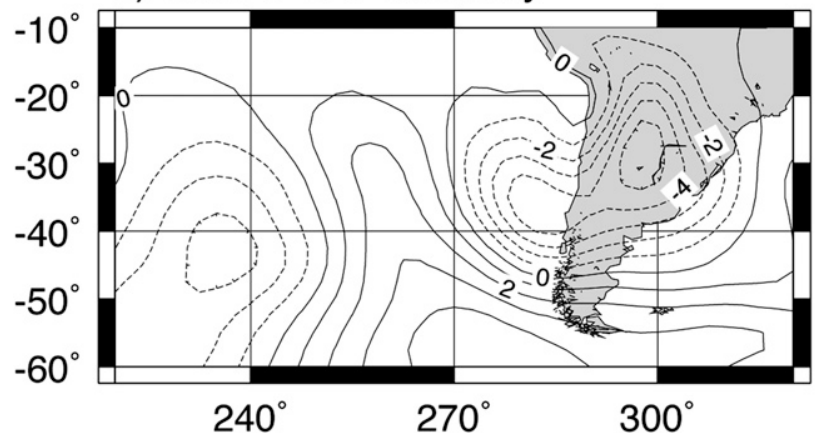

b) State 2 SLP anomaly

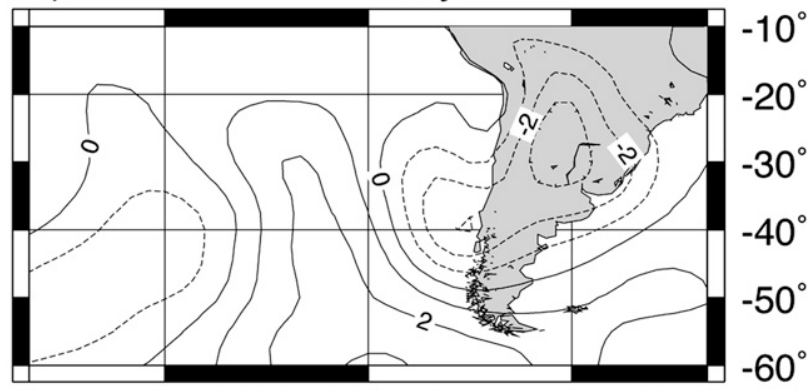

d) State 4 SLP anomaly

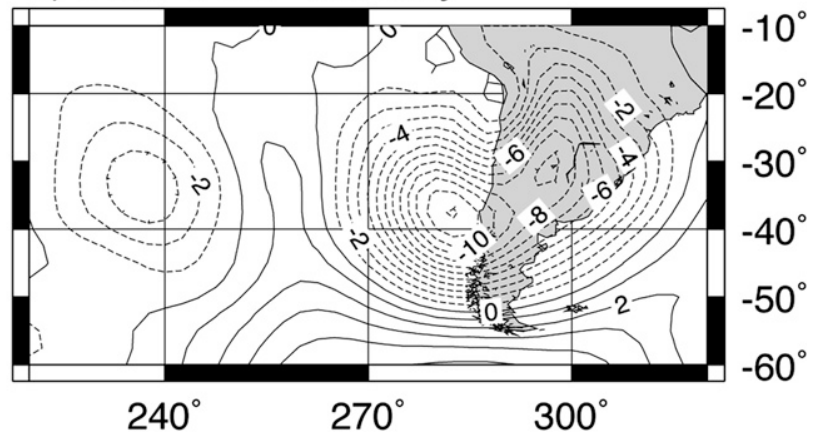

FIG. 7. Composites of sea level pressure anomalies $(\mathrm{hPa})$ for each rainfall state. A finer contour interval is used in (a) for clarity.

significant at the $99 \%$ level according to a two-sided Student test. The Spearman correlation coefficient, which is less sensitive than the Pearson correlation to strong outliers, was lower (0.45), but still significant. When only ENSO years are included, as defined by those years where positive or negative anomalies of one standard deviation $\left( \pm 0.6^{\circ} \mathrm{C}\right)$ were observed for the Niño-3.4 index, the Pearson correlation increases to 0.83 , which is indicative for the strength of the ENSO signal in extreme wet or dry years. The Spearman correlation coefficient was 0.80 , suggesting only a limited influence of outliers.
Table 3 shows the correlations between the observed station-averaged MJJA rainfall amount, frequency, and intensity and the cross-validated hindcasts from multiple linear regressions with the Niño-3.4 index averaged over different time periods as a predictor. Correlations are strongest when the Niño-3.4 index is contemporaneous or follows the MJJA season, consistent with the so-called ENSO spring predictability barrier around May; once established during boreal summer, ENSO events tend to persist into the following boreal fall. The hindcasts with the February-May (FMAM)-averaged

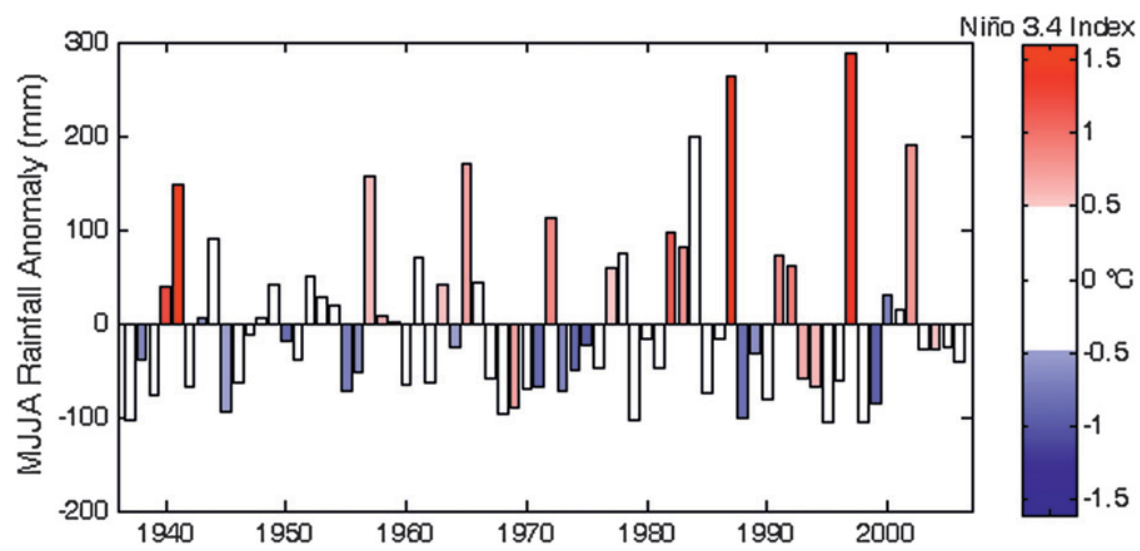

FIG. 8. Station-averaged MJJA rainfall amount, colored according to the sign and magnitude of the Niño-3.4 SST index for the period 1937-2005. 
TABLE 3. Pearson correlation coefficients between the observed station-averaged seasonal RAm, RF, and RI, and the cross-validated hindcasts using the average Niño-3.4 index (1937-2006) for different months and multimonth periods as a predictor. NDJF represents November-February.

\begin{tabular}{lrrrrrr}
\hline \hline & \multicolumn{6}{c}{ Avg Niño-3.4 index } \\
\cline { 2 - 7 } & FMAM & March & April & May & MJJA & NDJF \\
\hline RAm & 0.26 & 0.15 & 0.32 & 0.44 & 0.57 & 0.39 \\
RF & 0.33 & 0.23 & 0.36 & 0.49 & 0.59 & 0.39 \\
RI & -0.29 & -0.42 & -0.09 & 0.03 & 0.20 & 0.19 \\
\hline
\end{tabular}

Niño-3.4 index or even for individual months March, April, and May, were only weakly correlated with the MJJA total rainfall data, with Pearson correlations of $0.26,0.15,0.32$, and 0.44 respectively, limiting the prediction potential of the Niño-3.4 index. Similar behavior was found for rainfall frequency, with highest Pearson correlation for the contemporaneous period, whereas rainfall intensity was weakly correlated when using the Niño-3.4 index as a predictor for all periods considered (Table 3).

\section{d. ENSO influence on rainfall states}

Year-to-year variations in the frequency of the four rainfall states were correlated with the MJJA-averaged Niño-3.4 index, resulting in Pearson correlation coefficients of $-0.44,0.27,0.18$, and 0.52 , respectively (all are significant at the $95 \%$ level, except for state 3 ). Thus the ENSO relationship discussed above is mostly expressed in terms of the frequency of occurrences of states 1 and 4 . This is remarkable, given the small number of days falling into state 4 and its association with the most-intense storms, and demonstrates the strong relationship between El Niño and intense storms in central Chile.

El Niño events tend to weaken the subtropical anticyclone and to displace the frontal storms to more northern locations than normal with a blocking of their usual path further to the south (Garreaud and Battisti 1999; Rutllant and Fuenzalida 1991). This is consistent with our finding of a positive correlation between the occurrence of the three wet states and the ENSO index. When evaluating wet years, Rutllant and Fuenzalida (1991) found that a low-pressure zone becomes established over central Chile and northwestern Argentina, separating the Pacific anticyclone from the Atlantic high pressure area, which is consistent with the observed atmospheric circulation patterns observed for states 2 to 4 that exhibit an anomalous synoptic trough between $30^{\circ}$ and $40^{\circ} \mathrm{S}$, and a ridge to the south (Fig. 7).

\section{e. Seasonal prediction of daily rainfall aggregates}

Given the impact of ENSO on Coquimbo region rainfall documented in the previous subsections, we next explore the seasonal predictability of the observed rainfall based on GCM retrospective forecasts. In this subsection, we consider the seasonal aggregate scale, using the canonical correlation analysis described in section $3 \mathrm{c}$ to regress the GCM seasonal-averaged rainfall predictions onto the observed station seasonal rainfall statistics presented in section 4a. Scatterplots of the cross-validated seasonal rainfall deterministic forecasts are shown in Fig. 9 over the hindcast period (1981-2000) for each of the three GCMs, where each circle represents the forecast mean of the seasonal rainfall amount for each station year. A clear deviation from the 1:1 line is observed for the ECHAM-CA model, indicating clear underestimation of the higher rainfall amounts observed during wet years. The CCM-CA model shows an overestimation at the lower rainfall amounts, while failing to predict the more extreme rainfall values. The CFS model performs best, showing the least scatter as well as quite successful predictions in the higher range of rainfall amounts. This is confirmed by Table 4, which gives the stationaveraged root-mean-square error (RMSE), mean error
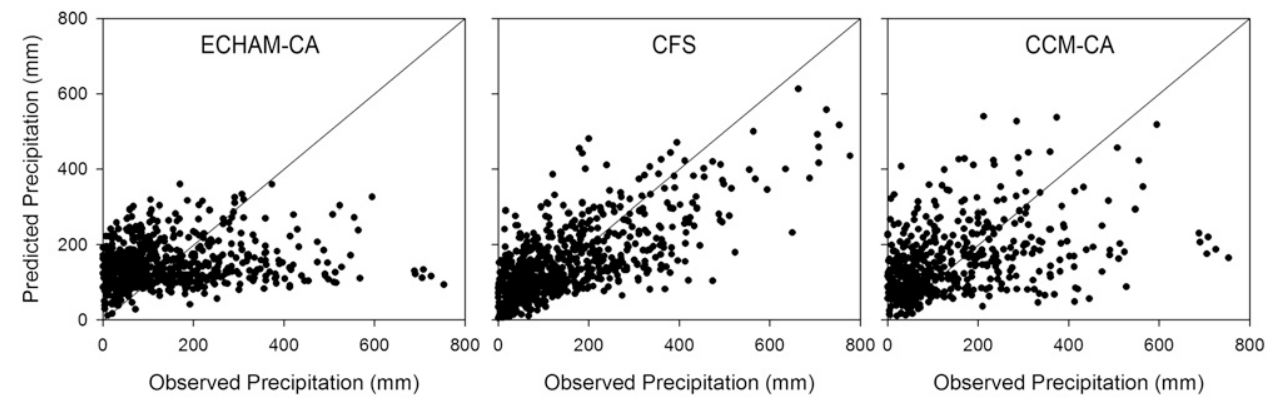

FIG. 9. Cross-validated hindcasts vs observed precipitation amounts using CCA for the three GCMs for the period 1981-2000, where each circle represents the value for each station, for each year. Thus, there are $42 \times 20$ circles in each panel. 
TABLE 4. The $\rho$, ME, and RMSE for cross-validated CCA hindcasts of seasonal rainfall amount with the ECHAM-CA, CFS, and CCM-CA models for the period 1981-2000.

\begin{tabular}{lccc}
\hline \hline & $\rho$ & ME $(\mathrm{mm})$ & RMSE $(\mathrm{mm})$ \\
\hline ECHAM-CA & $0.41^{*}$ & -9.74 & 133.54 \\
CFS & $0.69^{*}$ & -8.45 & 99.92 \\
CCM-CA & $0.17^{*}$ & -2.24 & 137.73 \\
\hline
\end{tabular}

* Correlation is significant at significance level $\alpha=0.05$.

or bias (ME), and Pearson correlation coefficients $(\rho)$ for each of the model (cross validated) retrospective forecasts of station precipitation. The CCM-CA gave the lowest correlation and the highest RMSE, but was the least biased, with a low ME. Correlation was higher for the ECHAM-CA, but ME and RMSE indicated an important bias in comparison to the other models. The CFS model showed the highest correlation coefficient and a low RMSE, but with a negative ME, underestimating the observed rainfall amounts at the highest observed rainfall amounts (e.g., $36 \%$ at $500 \mathrm{~mm}$ ). Nevertheless, the CFS model was selected for further processing because of its superior correlation statistics. Since seasonal MJJA hindcasts for the period 1981-2005 were available for the CFS model, this period was used for further analysis.
The Pearson correlation skill map from CFS for all stations (Fig. 10) shows a good correlation between observed and hindcast precipitation for almost all stations, with individual correlations between 0.57 and 0.80 . This could be expected, because of the high Pearson correlation skill ( $\rho$ was 0.76 ) of the CFS to predict Niño3.4 SST, when initialized on 1 April, and a high correlation ( $\rho$ of 0.82) between the leading PC of the gridded CFS rainfall and Niño-3.4 SST, which explains large part of the variability in rainfall amounts observed (see Fig. 8). A similar picture emerges for rainfall frequency, with slightly lower Pearson skill (0.20-0.63), while the correlation coefficients for rainfall intensity are generally much lower (from -0.15 to 0.64 ).

\section{f. Seasonal prediction of stochastic daily rainfall sequences}

Having addressed the seasonal predictability of daily rainfall aggregates (seasonal amount, rainfall frequency, and mean daily intensity) in the previous subsection, we next use the nHMM as described in section $3 b$ to derive seasonal forecasts of daily rainfall sequences at each of the stations. The nHMM used here builds on the HMM results presented in sections $4 \mathrm{~b}$ and $4 \mathrm{~d}$, but with the inclusion of CFS forecasts of MJJA seasonal-averaged precipitation, as described in section $3 \mathrm{~b}$. This is the same (a) Seasonal Rainfall Amount

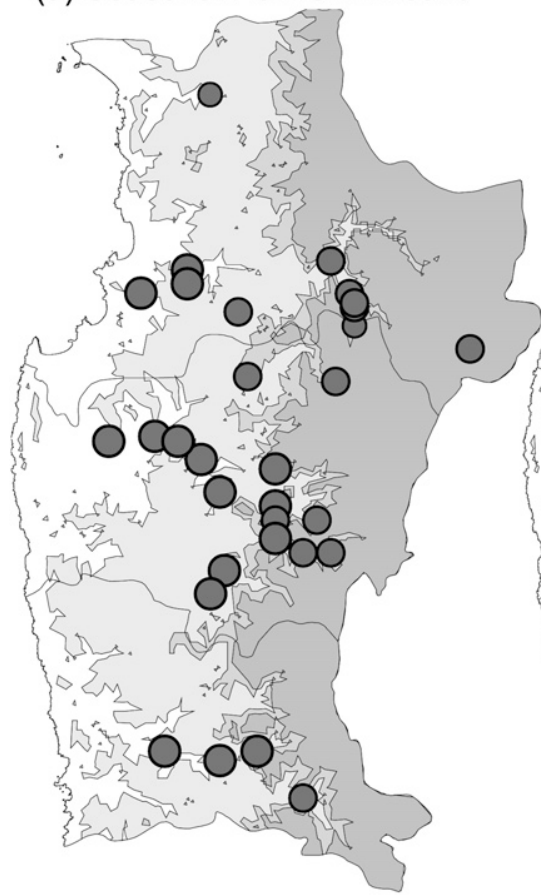

(b) Rainfall Frequency

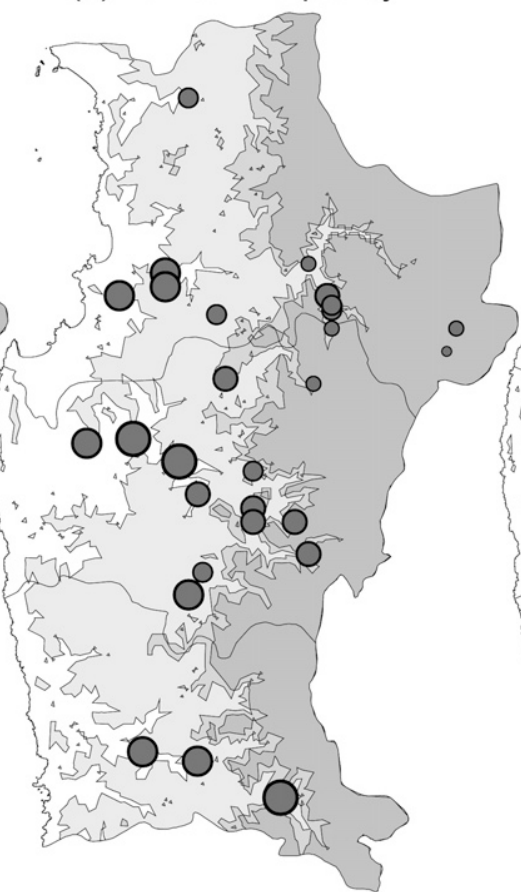

(c) Rainfall Intensity

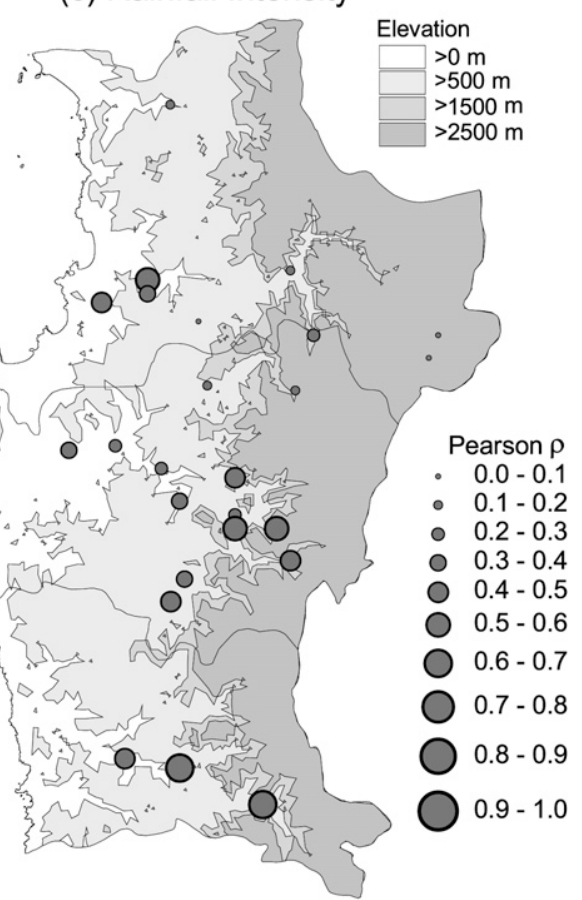

FIG. 10. Pearson correlation between CFS hindcasts downscaled using CCA and observed rainfall for (a) seasonal rainfall amount, (b) rainfall frequency, and (c) mean rainfall intensity for the period 1981-2005. 
(a) Seasonal Rainfall Amount

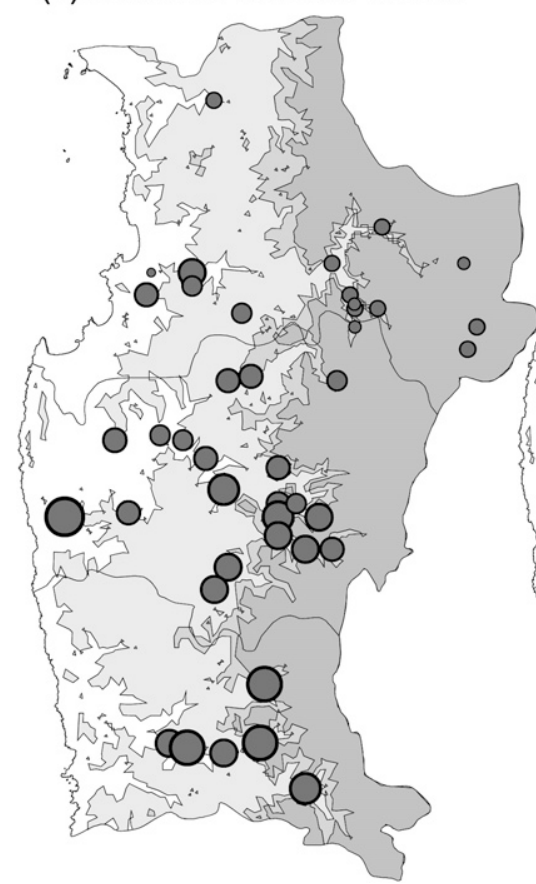

(b) Rainfall Frequency

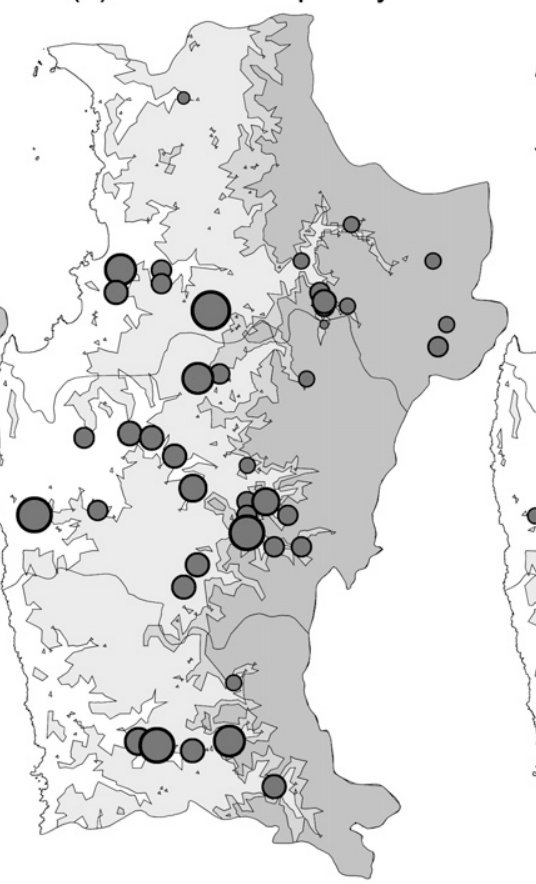

(c) Rainfall Intensity

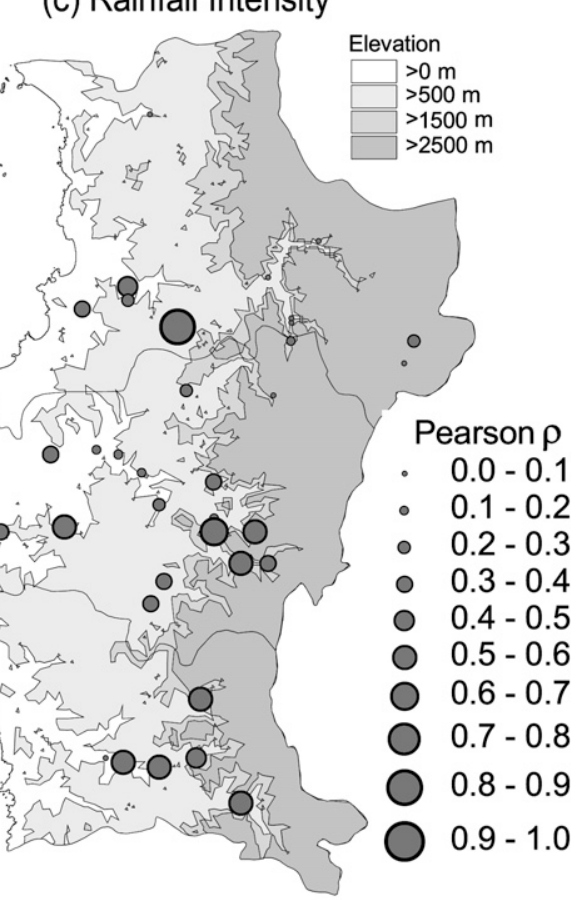

FIG. 11. As Fig. 10, but for CFS downscaled rainfall obtained using the nHMM and taking the ensemble mean over the 150 nHMM simulations.

CFS predictor field used via CCA in the previous subsection.

The resulting daily rainfall simulations were then used to construct the seasonal rainfall amount, rainfall frequency, and mean daily intensity, and the ensemble averages then correlated with observed values (Fig. 11). As in the case of the CCA-based forecasts in Fig. 10, correlations were generally higher for seasonal rainfall amount and rainfall frequency, compared with rainfall intensity, with station values ranging from $0.17-0.92$, $0.19-0.92$, and $-0.38-0.84$ for the three quantities, respectively. Interstation differences in skill are larger than in the CCA approach, but fewer stations with negative correlations were obtained using the nHMM (note that only positive values are plotted in Figs. 10 and 11).

Time series of the station-averaged MJJA seasonal rainfall statistics are plotted in Fig. 12, which compares the median and interquartile range of the 150-member ensemble of nHMM simulations, together with the observed values and CCA-based hindcasts. The hindcasts of seasonal rainfall amount obtained using both methods (CCA and nHMM) follow the observed highs and lows reasonably well (Fig. 12a), with a Pearson correlation skill for the CCA of 0.77 and for the nHMM mean of 0.62. A small overestimation for the nHMM low rainfall amount years is observed, as well as an underestimation when dealing with very wet years, and can be attributed to the deviations observed between the CFS model predicted and observed precipitation (Table 4 and Fig. 9).

The rainfall frequency hindcasts from the nHMM were also skillful $(\rho=0.55)$, representing the observed interannual variability better than for rainfall intensity $(\rho=0.30)$. The underestimated mean rainfall intensities in 1984 resulted in an important underestimation of the seasonal rainfall amount for nHMM, while the CCA hindcast of seasonal amount was less affected. The year 1983, on the other hand, had more rainfall days than picked up by the nHMM and CCA, but with low intensities, still resulting in acceptable predictions of the seasonal rainfall amount with both methods.

\section{g. Toward a drought early warning system}

Although no effort was made to design or setup a drought early warning system for the Coquimbo region, this paper tries to identify the prediction potential of meteorological drought indices that would be essential to such an effort. To tailor our rainfall hindcasts more specifically to drought indicators, we first express our hindcasts in terms of the standardized precipitation index (SPI; Edwards and McKee 1997; McKee et al. 1993), a commonly used meteorological drought classification method. The SPI is derived by transforming the probability distribution of (here seasonal amount) rainfall into 

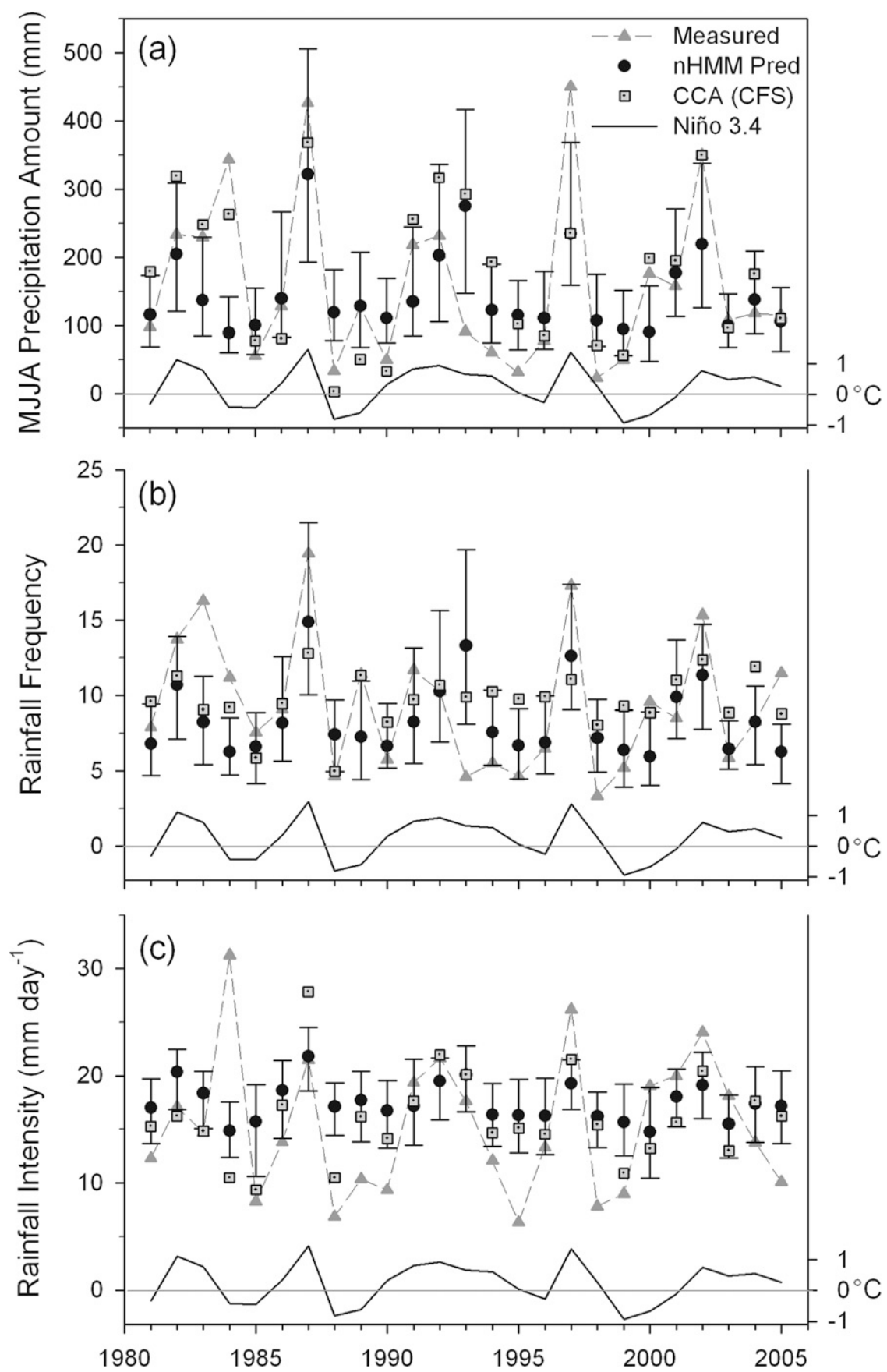

FIG. 12. Comparison of station-averaged downscaling results obtained from CFS using CCA and the nHMM for (a) seasonal rainfall amount, (b) rainfall frequency, (c) mean rainfall intensity. The error bars indicate the 25 th and 75 th percentiles of the simulated nHMM ensemble values. The Niño-3.4 index is also indicated.

a unit normal distribution so that the mean SPI is zero and each value is categorized in one of its five quantiles and, as such, given a drought class. The SPI hindcasts derived from the CFS using the CCA and nHMM methods are shown in Fig. 13, together with those derived from the (simultaneous) cross-validated regression with MJJA Niño-3.4 SST. Each of the methods was able to represent observed SPI variability rather well, although different SPI classes were often predicted. This is reflected in Table 5, where fits between observed and simulated SPIs 


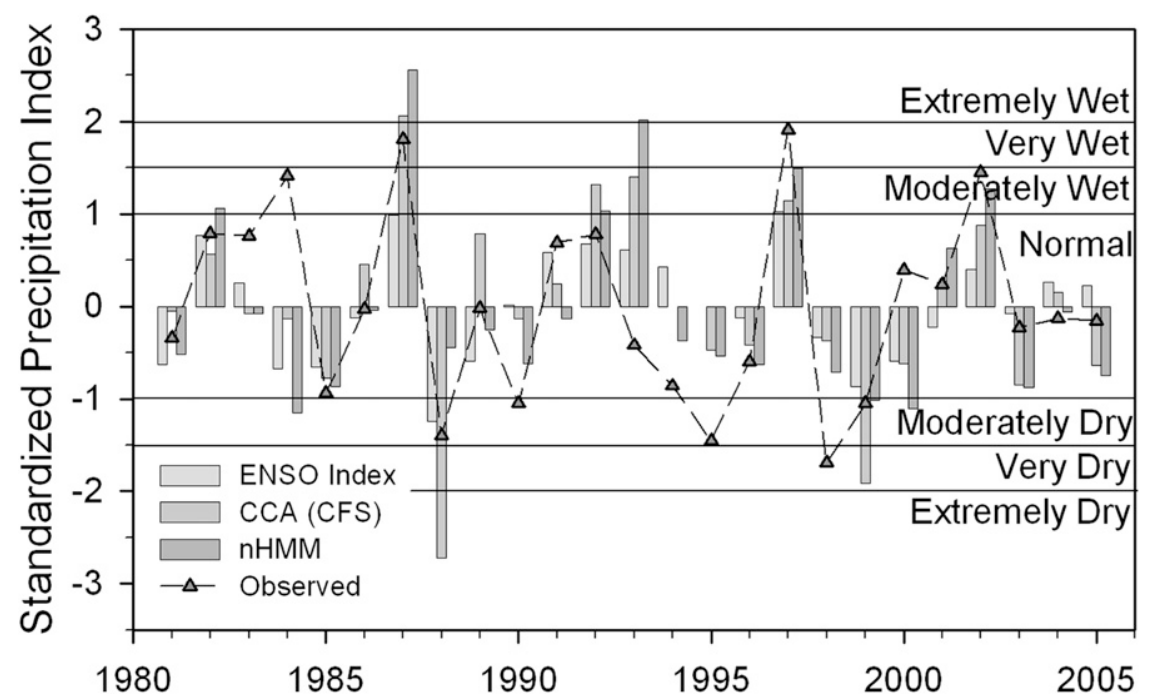

FIG. 13. Station-averaged hindcasts of the SPI obtained from the MJJA Niño-3.4 index, and the CFS downscaled with CCA and with the nHMM. The SPI values constructed from observed station rainfall are also plotted.

are expressed in terms of $\rho, \mathrm{ME}, \mathrm{RMSE}$, and hit rate. None of the prediction models showed a significant bias, because the standardization of the SPI, and the Pearson correlation values are similar to those of the seasonal rainfall amount. The hit rate measures the success of the method to predict the SPI class, and substantially exceeds the $20 \%$ rate expected by chance. When interested in general trends, the hit rate might be too strict to evaluate the prediction skill. For example, for the year 1987 CCA and nHMM predicted SPI values of 2.1 and 2.6, respectively (extremely wet); whereas, the observed SPI value was 1.8 (very wet), reducing the hit score although the prediction was rather accurate. When accepting model predictions that are one SPI class lower, equal to or one class higher than the observed SPI class, the hit rate increased to values of $92 \%, 92 \%$, and $88 \%$ for the ENSO index, the CCA method and the nHMM, respectively, indicating that the general trend (dry, wet, or normal) is maintained by the three methods.

In a second approach, the nHMM hindcasts of daily rainfall series were converted into two different daily drought indices and compared with observed values. As a first index, the frequency of days with substantial rainfall ( $>15 \mathrm{~mm} \mathrm{day}{ }^{-1}$ ) was used to classify years with drought risk, hereafter named FREQ15. A second drought index based on daily rainfall is the accumulated precipitation deficit (APD), derived from the work of Byun and Wilhite (1999), which gives a simple accumulation of daily precipitation deficit from May to August, and was found to be a good measure for drought intensity.

In general, the drought indices obtained from the nHMM cross-validated hindcasts closely followed the observed indices for the period 1981-2005, with comparable and good fits for both the FREQ15 and the APD index ( $\rho=0.63$ and 0.60 , respectively). The observed versus predicted values of FREQ15 and APD are plotted in Fig. 14, which shows the median and the interquartile range (IQR) of the nHMM ensemble, showing information about the predicted distributions. The spread of the forecasts can be evaluated in terms of the IQR, which should bracket the observations in $50 \%$ of the years to be well calibrated, with lower values indicating too little spread and values above $50 \%$ for those forecast distributions with too much spread. For both drought indices, the interquartile range brackets the observed values in $44 \%$ and $52 \%$ of the years, respectively, indicating that the forecasts are rather well calibrated.

To quantify the skill of these probabilistic forecasts, the ranked probability skill score (RPSS) is used, which is a squared error metric that allows measuring the distance between the cumulative distribution function of the forecast and the verifying observation, and is expressed with respect to a baseline given by the climatic forecast

TABLE 5. The $\rho$, ME, RMSE, and hit rate for hindcasts expressed in terms of the station-averaged SPI. The hindcasts were made based on the MJJA Niño-3.4 index, and the CFS downscaled with CCA or the nHMM.

\begin{tabular}{lccc}
\hline \hline & Niño-3.4 index & CCA & nHMM \\
\hline$\rho$ & 0.56 & 0.65 & 0.58 \\
ME & -0.01 & -0.01 & 0.00 \\
RMSE & 0.17 & 0.17 & 0.18 \\
Hit rate* $\%)$ & 68.0 & 56.0 & 60.0 \\
\hline
\end{tabular}

* Defined as the percentage of correct SPI class prediction. 

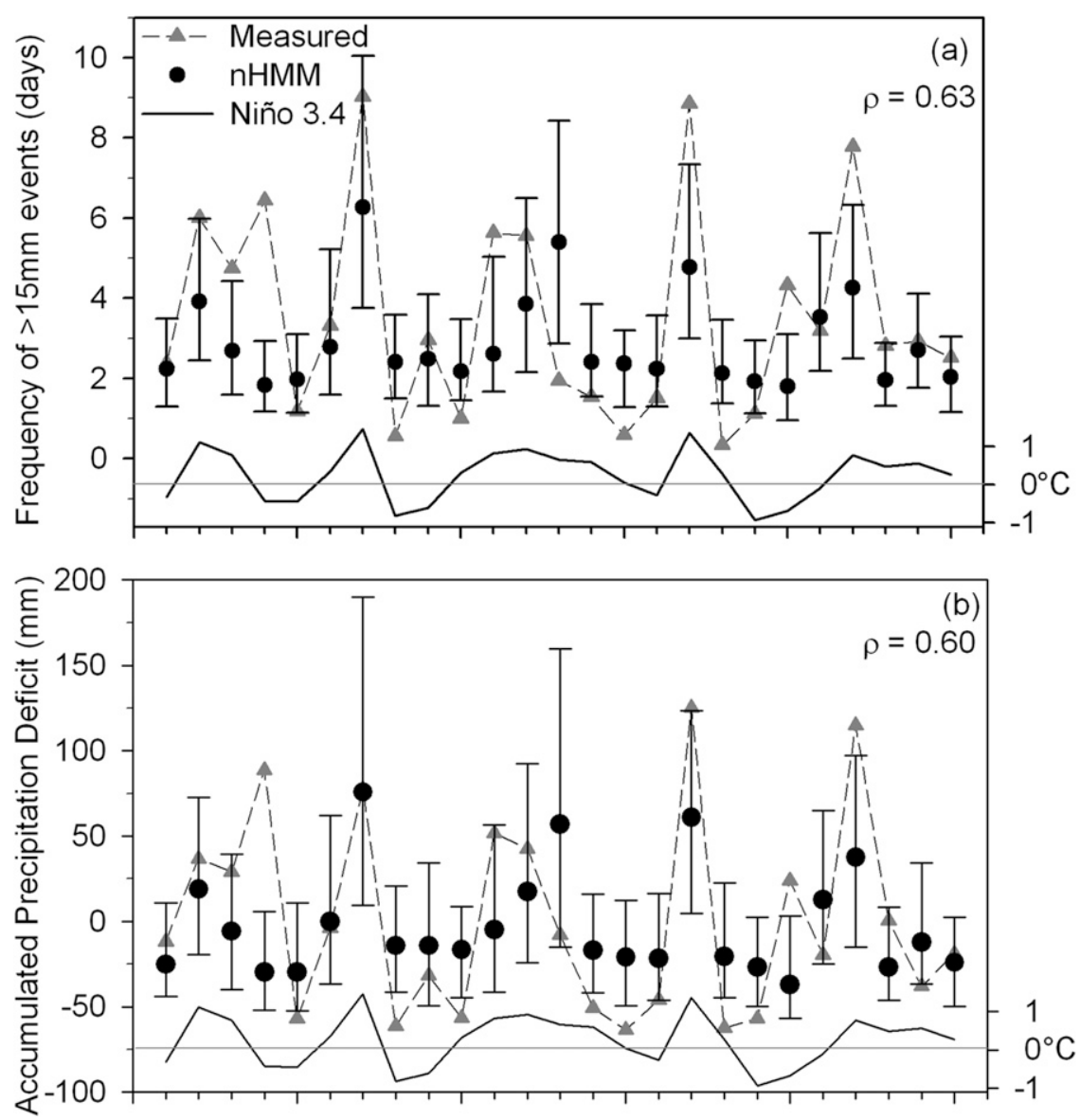

FIG. 14. Hindcasts of two station-averaged meteorological drought indices (circles) consisting of (a) FREQ15, and (b) APD, based on the nHMM simulations, compared with values constructed from observed daily rainfall (dashed). The error bars indicate the 25 th and 75 th percentiles of the nHMM ensemble. The Niño-3.4 index is also indicated.

distribution. A perfect forecast would be represented by an RPSS of $100 \%$, while negative values indicate that the forecast is less skillful than the climatological equalodds forecast. For the two indices under consideration, the station-averaged median RPSS values were 25.2 for FREQ15 and 12.3 for APD, indicating better than climatology forecasts in both cases. Additionally, the percentages of positive RPSS values were found to be $84 \%$ and $80 \%$, respectively, confirming the good predictability of FREQ15 and APD. In Fig. 15 the median RPSS is presented for each station for FREQ15 and APD, showing similar results as the station average, with few areal differences, but suggests a superior predictability of FREQ15 compared to APD.

Both indices can also be related to declared drought years in the Coquimbo region (Novoa-Quezada 2001), as defined by seasonal rainfall amounts not exceeding a minimum threshold to recharge the topsoil during the wet season (e.g., $207 \mathrm{~mm}$ in the southwestern part of the Coquimbo region), when evaluated with a regional water balance method. Since both FREQ15 and APD showed a correlation of 0.87 with declared drought years, their relatively good predictability is especially encouraging for climate risk management purposes.

\section{Summary and conclusions for dry-land management}

Rainfall variability is known to be a major economic and social disruptor in the central northern area of Chile, with large financial consequences for society when both extreme drought and extreme wet conditions occur. A low preparedness could be partly responsible for the large impact of these events. Therefore, the Chilean government has supported the development of a climate risk management system for the semiarid regions of Chile to reduce the vulnerability and increase resistance to extreme climatic events. An early warning system for 
(a) Frequency $>15 \mathrm{~mm}$ Rainfall Events (FREQ15) (b) Accummulated Precipitation Deficit (APD)

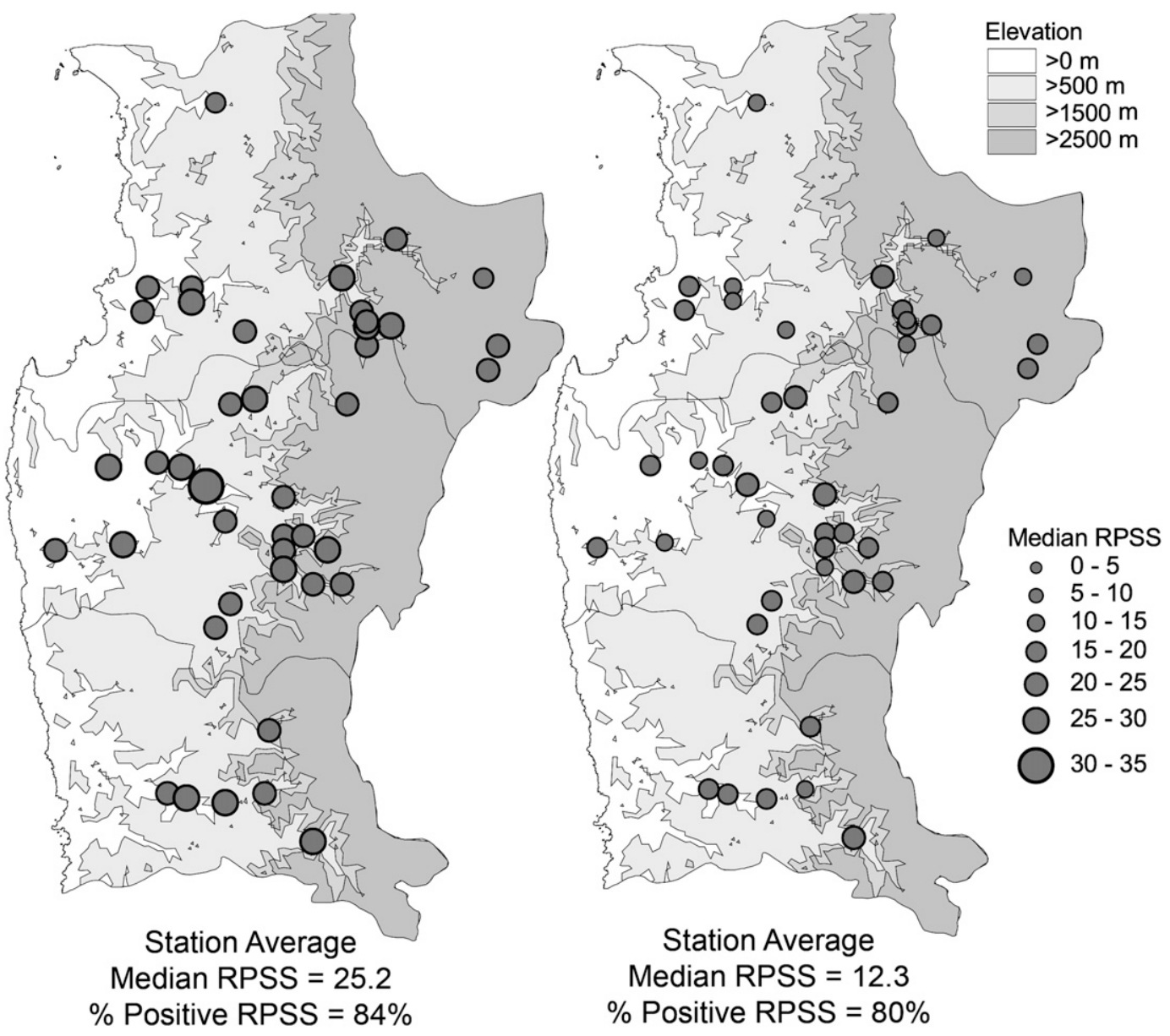

FIG. 15. Median RPSS for hindcasts of (a) FREQ15 and (b) APD constructed from the nHMM simulations.

droughts and floods would be an essential component of such an approach, which requires estimation and prediction of the rainfall characteristics relevant to drought as a first step.

Winter rainfall characteristics in the Coquimbo region of Chile were first investigated using daily rainfall records at 42 stations, with special attention to spatial and temporal characteristics and the relationship with ENSO. Seasonal rainfall amounts, daily rainfall frequencies, and mean daily rainfall intensities all generally increase southward and eastward toward the Andes (Fig. 3). An analysis of the spatial correlations between stations (Fig. 4) indicated large interstation correlations at the daily time scale, particularly for rainfall amount. The spatial coherence of rainfall amount and frequency was found to increase substantially with temporal averaging, suggesting the role of ENSO forcing at the seasonal scale. Seasonal anomalies of mean daily rainfall intensity were found to be less spatially coherent (Table 1), though their coherence was larger than found by Moron et al. (2007) for tropical rainfall, because of the frontal character of rainfall in the region.

The spatiotemporal evolution of daily rainfall patterns across the region was further elucidated in terms of four rainfall states identified using a hidden Markov model; these states consisted of dry and increasingly wet conditions (Fig. 5), the latter associated with near-stationary trough in sea level pressure, centered to the south and east of the region (Fig. 7). The daily sequences of these states showed sporadic rainfall events with little seasonality within the winter season (Fig. 6), while the likelihood of an intense storm across the region (state 4) was found to be strongly correlated with ENSO, thus providing an interpretation in terms of daily weather for the well-established seasonal rainfall relationship with ENSO (Fig. 8). 
Seasonal predictability of rainfall characteristics was explored firstly using a simple univariate index of ENSO; this proved only to be well correlated for simultaneous (May or MJJA) values of the index, and thus not useful for prediction since lead times are insufficient for drought prediction. Rainfall intensities were found not to be well correlated. Predictability was further explored using a GCM to forecast MJJA rainfall amounts. In our approach, the GCMs were initialized with 1 April climate and/or oceanic conditions of each year 1981-2005, presenting as such a real prediction with lead times up to four months. Of three the GCMs considered (ECHAM-CA, CCM-CA, and CFS), the highest skill and lowest bias was obtained for the CFS model (Fig. 9; Table 4). The CFS was then downscaled to represent local variability in station data, using two different techniques. First, a canonical correlation analysis (CCA) approach was developed to map GCM forecasts of seasonal precipitation to seasonal rainfall characteristics (seasonal rainfall amount, daily rainfall frequency, mean daily rainfall intensity on wet days) at each rainfall station. Second, a nonhomogeneous HMM was used to derive ensembles of stochastic daily rainfall sequences at each station as a function of GCM seasonally averaged rainfall; the seasonal rainfall characteristics were then calculated from these simulated daily sequences. For both downscaling methods the skill for seasonal rainfall amount, frequency, and mean daily intensity examined at the station scale (Figs. 10-12) produced similar results. The highest correlations with observations were found for seasonal rainfall amount and rainfall frequency for most measuring stations in the region, but low or negative correlations for rainfall intensity. These differences in skill are consistent with differences in the spatial coherence of station-scale seasonal rainfall anomalies (Table 1), with mean daily rainfall intensity being less spatially coherent and thus less predictable than seasonal amount and daily frequency (Moron et al. 2007).

Since the objective of the work is oriented toward the development of a drought early warning system for dry-land management, the (retrospective) forecasts of rainfall were then tailored for drought prediction. Following the recommendations of the World Meteorological Organization (Declaration on Drought Indices, 11 December 2009, available online at http://www.unced. int/publicinfo/wmo/docs/LincolnDeclaration.pdf), the standardized precipitation index, which was calculated from seasonal rainfall amounts, was used as a proxy for meteorological drought. The SPI was forecast with both the CFS-CCA and CFS-nHMM approach and compared with observed values, showing that the SPI was quite well forecast by both methods (Fig. 13).
For some end-user applications, the seasonal-averaged SPI may be too coarse, and drought indices based on daily weather statistics may be more appropriate. Motivated by the potential needs for dry-land management, the nHMM was used to forecast two additional drought indices based on daily rainfall statistics, showing high correlations with observations and positive prediction skill for all stations when using the frequency of occurrence of days exceeding $15 \mathrm{~mm} \mathrm{day}^{-1}$ (FREQ15) and the accumulated daily precipitation deficit (APD). While the CCA could also be applied to these statistics, calculating the appropriate predictand from daily observed data, the daily rainfall sequences simulated by the nHMM have the potential to be used in pasture and crop models that require daily weather sequences (e.g., Robertson et al. 2007).

Downscaled seasonal predictions of seasonal and daily rainfall characteristics and related meteorological drought indices have been shown feasible for the Coquimbo region. This could be regarded as an important step in the development of a tailored climate risk management system that should contribute to reduce climate uncertainty in a region that is affected by high rainfall variability. The approach presented in this paper could eventually be extended to forecast agricultural and/or hydrological drought conditions, for which high spatial and temporal resolution of downscaled predictions is required, such as provided by the nHMM approach. The methodology for predicting the nature of within-season daily rainfall variability presented in this paper is also likely to be successful in other regions where daily rainfall variability can be linked to predictable large-scale climatic patterns.

Acknowledgments. The authors thank the Chilean Water Authority (Dirección General de Aguas) for providing the daily rainfall series of the Coquimbo region and the three anonymous reviewers for their helpful comments to improve the manuscript. This research was funded by the Flemish Government, Department of Sciences and Innovation/Foreign Policy, the UNESCO Regional Office for Science and Technology in Latin America and the Caribbean, and by National Oceanic and Atmospheric Administration Grant NA050AR4311004 and the U.S. Department of Energy's Climate Change Prediction Program Grant DE-FG02-02ER63413.

\section{REFERENCES}

Aceituno, P., 1988: On the functioning of the Southern Oscillation in the South American sector. Part I: Surface climate. Mon. Wea. Rev., 116, 505-524.

_ M. Prieto, M. Solari, A. Martínez, G. Poveda, and M. Falvey, 2009: The 1877-1878 El Niño episode: associated impacts in South America. Climatic Change, 92, 389-416. 
Barnston, A. G., S. Li, S. J. Mason, D. G. DeWitt, L. Goddard, and X. Gong, 2010: Verification of the first 11 years of IRI's seasonal climate forecasts. J. Appl. Meteor. Climatol., 49, 493-520.

Bellone, E., J. P. Hughes, and P. Guttorp, 2000: A hidden Markov model for downscaling synoptic atmospheric patterns to precipitation amounts. Climate Res., 15, 1-12.

Byun, H.-R., and D. A. Wilhite, 1999: Objective quantification of drought severity and duration. J. Climate, 12, 2747-2756.

Charles, S. P., B. C. Bates, P. H. Whetton, and J. P. Hughes, 1999: Validation of downscaling models for changed climate conditions: case study of southwestern Australia. Climate Res., 12, 1-14.

Dai, A., I. Y. Fung, and A. D. del Genio, 1997: Surface global observed land precipitations variations: $1900-1988$. J. Climate, 10, 2943-2962.

Dempster, A. P., N. M. Laird, and D. R. Rubin, 1977: Maximum likelihood from incomplete data via the EM algorithm. J. Roy. Stat. Soc., 39B, 1-38.

Edwards, D. C., and T. B. McKee, 1997: Characteristics of 20th century drought in the United States at multiple time scales. Climatology Rep. 97-2, Department of Atmospheric Science, Colorado State University, $155 \mathrm{pp}$.

Falvey, M., and R. Garreaud, 2007: Wintertime precipitation episodes in central Chile: Associated meteorological conditions and orographic influences. J. Hydrometeor., 8, 171-193.

Forney, G. D., 1978: The Viterbi algorithm. Proc. IEEE, 61, 268-278.

FOSIS, 2008: Superando la sequía. Plan especial para familias vulnerables de zonas rurales afectadas por la sequía (Overcoming the drought. Special plan for vulnerable families in rural areas affected by drought). Fondo de Solidaridad e Inversión Social, $11 \mathrm{pp}$.

Garreaud, R. D., and D. S. Battisti, 1999: Interannual (ENSO) and interdecadal (ENSO-like) variability in the Southern Hemisphere tropospheric circulation. J. Climate, 12, 2113 2122.

_-, M. Vuille, R. Compagnucci, and J. Marengo, 2009: Presentday South American climate. Palaeogeogr. Palaeoclimatol. Palaeoecol., 281, 180-195.

Ghahramani, Z., 2001: An introduction to hidden Markov models and Bayesian networks. Int. J. Pattern Recognit. Artif. Intell., 15, 9-42.

Goddard, L., A. G. Barnston, and S. J. Mason, 2003: Evaluation of the IRI's "Net Assessment" seasonal climate forecasts: 1997_ 2001. Bull. Amer. Meteor. Soc., 84, 1761-1781.

Hughes, J. P., and P. Guttorp, 1994: A class of stochastic models for relating synoptic atmospheric patterns to regional hydrologic phenomena. Water Resour. Res., 30, 1535-1546.

Hurrell, J. W., J. J. Hack, B. A. Boville, D. L. Williamson, and J. T. Kiehl, 1998: The dynamical simulation of the NCAR Community Climate Model version 3 (CCM3). J. Climate, 11, 1207-1236.

Kalnay, E., and Coauthors, 1996: The NCEP/NCAR 40-Year Reanalysis Project. Bull. Amer. Meteor. Soc., 77, 437-471.

Katz, R. W., and M. H. Glantz, 1986: Anatomy of a rainfall index. Mon. Wea. Rev., 114, 764-771.

Kumar, A., Q. Zhang, J.-K. E. Schemm, M. Heureux, and K.-H. Seo, 2008: An Assessment of errors in the simulation of atmospheric interannual variability in uncoupled AGCM simulations. J. Climate, 21, 2204-2217.

Li, S., and L. Goddard, 2005: Retrospective forecasts with the ECHAM4.5 AGCM. IRI Tech. Rep. 05-02. IRI, 16 pp.
McKee, T. B., N. J. Doesken, and J. Kliest, 1993: The relationship of drought frequency and duration to time scales. Proc. Eighth Conf. on Applied Climatology, Anaheim, CA, Amer. Meteor. Soc., 179-184.

MINAGRI, 2008: Advances in the execution of agricultural emergencies: June 16, 2008 (in Spanish). Chilean Ministry of Agriculture Rep., 42 pp.

Montecinos, A., and P. Aceituno, 2003: Seasonality of the ENSOrelated rainfall variability in central Chile and associated circulation anomalies. J. Climate, 16, 281-296.

Moron, V., A. W. Robertson, M. N. Ward, and P. Camberlin, 2007: Spatial coherence of tropical rainfall at the regional scale. J. Climate, 20, 5244-5263.

New, M., M. Hulme, and P. Jones, 2000: Representing twentiethcentury space-time climate variability. Part II: Development of 1901-96 monthly grids of terrestrial surface climate. J. Climate, 13, 2217-2238.

Novoa-Quezada, P., 2001: Determinación de condición de sequía por análisis de la variación de humedad del horizonte radicular usando el modelo de simulación Hidrosuelo (Determining the drought condition by analyzing the moisture variation in the root zone using the Hidrosuelo simulation model). CONAF, Viña del Mar, Chile, 44 pp.

Pittock, A. B., 1980: Patterns of climatic variation in Argentina and Chile. Part I: Precipitation, 1931-1960. Mon. Wea. Rev., 108, 1347-1361.

Quinn, W., and V. Neal, 1983: Long-term variations in the Southern Oscillation, El Niño and the Chilean subtropical rainfall. Fish Bull., 81, 363-374.

Ricciardulli, L., and P. D. Sardeshmukh, 2002: Local time- and space scales of organized tropical deep convection. J. Climate, 15, 2775-2790

Robertson, A. W., S. Kirshner, and P. J. Smyth, 2004: Downscaling of daily rainfall occurrence over northeast Brazil using a hidden Markov model. J. Climate, 17, 4407-4424.

,-- P. C. Smyth, S. P. Charles, and B. C. Bates, 2006: Subseasonal-to-interdecadal variability of the Australian monsoon over North Queensland. Quart. J. Roy. Meteor. Soc., 132, 519-542.

- A. V. M. Ines, and J. W. Hansen, 2007: Downscaling of seasonal precipitation for crop simulation. J. Appl. Meteor. Climatol., 46, 677-693.

— V. Moron, and Y. Swarinoto, 2009: Seasonal predictability of daily rainfall statistics over Indramayu district, Indonesia. Int. J. Climatol., 29, 1449-1462.

Roeckner, E., and Coauthors, 1996: The atmospheric general circulation model ECHAM-4: Model description and simulation of present-day climate. Max-Planck-Institut für Meteorologie Rep., 90 pp.

Rubin, M. J., 1955: An analysis of pressure anomalies in the Southern Hemisphere. Notos, 4, 11-16.

Rutllant, J., and H. Fuenzalida, 1991: Synoptic aspects of the central Chile rainfall variability associated with the Southern Oscillation. Int. J. Climatol., 11, 63-76.

Saha, S., and Coauthors, 2006: The NCEP Climate Forecast System. J. Climate, 19, 3483-3517.

Smith, D. F., A. J. Gasiewski, D. L. Jackson, and G. A. Wick, 2005: Spatial scales of tropical precipitation inferred from TRMM microwave imager data. IEEE Trans. Geophys. Remote Sens., 43, 1542-1551.

Tippett, M. K., M. Barlow, and B. Lyon, 2003: Statistical correction of central southwest Asia winter precipitation simulations. Int. J. Climatol., 23, 1421-1433. 